\title{
Ludwig Senfl, Herzog Albrecht und der Kelch des Heils
}

\author{
Für Markus, \\ den preußischen Sachsen-Anhalter.
}

Die lebhafte Korrespondenz zwischen Herzog Albrecht von BrandenburgPreußen, bis 1525 Großmeister des Deutschen Ordens und einer der ersten weltlichen Herrscher, die den reformatorischen Glauben annahmen und unterstützten, und Ludwig Senfl respektive Angestellten der Münchner Hofkapelle ist der wissenschaftlichen Forschung seit Moritz Fürstenaus Veröffentlichung von vier Briefen Senfls im Jahr I 863 bekannt. ${ }^{\mathrm{I}}$ Fürstenaus Publikation war jedoch nicht die erste, die auf diese Briefe einging, verwies er doch auf einen Artikel von Johann Voigt, in dem dieser bereits I852, und damit elf Jahre früher, auf den Briefverkehr Senfls mit Albrecht aufmerksam gemacht hatte. ${ }^{2}$ Im ersten und einzigen Band der geplanten Gesamtausgabe der Werke Ludwig Senfls in den Denkmälern der Tonkunst in Bayern, ${ }^{3}$ konnte Theodor Kroyer dieser Korres-

* Frühere Fassungen dieses Beitrages wurden auf der Tagung The Musical Heritage of the Jagiellonian Era in Central and Eastern European Countries Warsaw, National Library, 25-29 August 2009, wie auch während eines Gastvortrages im Rahmen der Leuven Lectures in Musicology an der Katholieke Universiteit Leuven gehalten. Mein herzlichster Dank gilt meinen Kollegen Sonja Tröster und Marko Motnik für ihre Hilfe und ihre unermüdliche Bereitwilligkeit zur Diskussion und geduldigen Beantwortung zahlreicher Fragen, sowie den Mitarbeitern des Geheimen Staatsarchives Preußischer Kulturbesitz in Berlin für ihre kompetente Beratung und ihre stets freundliche und zuvorkommende Hilfe.

I „Ludwig Senfl und Markgraf Albrecht, Herzog in Preussen“, in $A m Z$ N.F. I (I 863), Sp. 564569; siehe hierzu auch Robert Eitner, „Fünf Briefe von Lucas Wagenrieder von I 536-I $538^{\text {“, }}$ in $M f M 8$ (I 876), S. 25-29. Für einen Überblick über den gesamten bislang bekannten Briefwechsel von ca. I526-I550 sowie anderen Musikalienlieferungen an den preußischen Hof siehe Anhang I. Die Korrespondenz konnte für den vorliegenden Beitrag um zwei bislang unbekannte Briefe ergänzt werden.

2 Johann Voigt, „Deutsche Musik im I6. Jahrhundert, insbesondere am Hofe Albrecht's von Preussen“, in Germania 2 (I 852), p. 207-223, hier S. 209. Voigt selbst berichtet jedoch bereits 22 Jahre vorher aus dem Briefwechsel: Johann Voigt, „Musikliebhaberei des Herzogs Albrecht von Preußen“, in Allgemeines Archiv für die Geschichtskunde des Preußischen Staates 2 (I 830 ), S. 69-78. Leider bringt Voigt keinerlei Nachweise oder Belege für seine Ausführungen und erwähnt nur, dass ihm „ein Faszikel Briefe“ vorläge, „die meist an den Herzog Albrecht von Preußen gerichtet sind oder von diesem ausgehen."

3 Ludwig Senfls Werke, erster Teil, hrsg. von Theodor Kroyer, Leipzig I903 (DTB III/2). Kroyer kannte 23 Briefe und unternahm eine erste Diskussion des Briefwechsels. 
pondenz noch einen weiteren Brief hinzufügen, aber erst Martin Bente dokumentierte schließlich in seiner Dissertation von 1968 den mehr oder weniger vollständigen Briefwechsel zwischen München und Königsberg. ${ }^{4}$ Senfl war freilich weder der erste noch der einzige Musiker, mit dem Herzog Albrecht korrespondierte. Auf der Suche nach immer neuen und neuesten Werken für seinen Hof beauftragte Albrecht verschiedenste Agenten, die Augen nach aktueller Musikliteratur offen zu halten und erhielt von Komponisten wie Thomas Stoltzer und Johann Walther Werke, die z.T. ausdrücklich für ihn komponiert worden waren. ${ }^{5}$

Dem Briefverkehr mit Senfl bzw. mit Senfls Kollegen Lukas Wagenrieder und den herzoglichen Agenten bleibt dennoch eine Sonderstellung in der Korrespondenz Herzog Albrechts vorbehalten, dokumentiert er doch in ihrem derzeitigen außerordentlichen Umfang von 27 erhaltenen Dokumenten nicht nur die Freude, ja fast schon Gier, eines weltlichen Fürsten nach der „musica viva“ des I6. Jahrhunderts, er erlaubt auch umfassende und äußerst lebendige Einblicke in die Transferprozesse und die Rezeption von Musik in der ersten Hälfte des I6. Jahrhunderts. Da nur drei Briefe von Senfl persönlich an Albrecht adressiert wurden - auf die problematische Frage des tatsächlichen Schreibers kann hier nicht weiter eingegangen werden -, bleibt trotz einiger weniger privater Mitteilungen wie der Geburt von Senfls Tochter zu bezweifeln, ob aus dieser Korrespondenz auch auf ein engeres Verhältnis der beiden Männer geschlossen werden kann.

Ähnlich wie Pfalzgraf Ottheinrich bat Herzog Albrecht auch Senfl bzw. Wagenrieder kontinuierlich um Musik; sei es, dass ersterer ihm „tenores“ auskomponieren sollte, oder dass letzterer auf Nachfrage des Herzogs Abschriften von Kompositionen für ihn anfertigte, auch wenn sie nicht von Senfl waren. ${ }^{6}$ Bereits im Februar I 536 waren sogar so viele Kompositionen nach Königsberg geschickt worden, dass Wagenrieder um ein Inventar all jener gesandten Stücke bat, um Verdopplungen bei zukünftigen Sendungen zu vermeiden. Albrecht sandte die benötigte, heute verlorene Inventarliste, und es dürfte sich - wie Joseph Müller-

4 Martin Bente, Neue Wege der Quellenkritik und die Biographie Ludwig Senfls. Ein Beitrag zur Musikgeschichte des Reformationszeitalters, Wiesbaden I968, ab S. 3 I 2.

5 Siehe hierzu Voigt, „Deutsche Musik im I6. Jahrhundert“, passim; Robert Eitner, „Briefe von Thomas Stoltzer, Adrian Rauch und Silvester Raid“, in MfM 8 (I876), S. 65-70; ders., „Ein Brief von Jörg Hayd von I 545“, in ebda., S. 8If.; ders., „Zwei Briefe von Georg Wytzel.“, in MfM 8 (I 876), S. I 57-I 59 .

$6 \quad$ „... Ir wollet vns solche, ob sie schon nicht schweitzerisch, das sie sonnstenn nur kunstreich vnnd guth wherenn zu fertigenn“. Brief Herzog Albrechts an Lukas Wagenrieder vom 23. Juli I 536. Bente, Neue Wege, S. 334. 
Blattau I924 gezeigt hat ${ }^{7}$ - um ein äußerst umfassendes Repertoire gehandelt haben, das der Herzog in seiner Musikbibliothek gesammelt hatte, das im Verlauf der vergangenen Jahrhunderte und vor allem aufgrund der Wirren des Zweiten Weltkrieges fast vollständig verloren gegangen ist. ${ }^{8}$

Dokumente von Albrechts Sammlungstätigkeit sind erst erhalten, nachdem der Herzog das Deutschordensgebiet in ein erbliches Herzogtum umgewandelt und das Königsberger Schloss als Residenz seiner ständigen Hofhaltung bezogen hatte (I 525 ). Offenbar war das Musikinteresse des Herzogs schon seit längerer Zeit weithin bekannt, denn bereits am 6. Februar I 526 übersandte ihm Johann Walther das Lied Albrecht seyn wir worden tauft (5v.) und drei weitere Lieder zu fünf Stimmen, ${ }^{9}$ dazu das Angebot für den Herzog, auch weiterhin auf Wunsch Liedsätze zu schreiben. ${ }^{{ }^{\circ}}$ Walther bemühte sich sehr darum, den Herzog musikalisch auf dem Laufenden zu halten und ihm „brandneue“ Musik zukommen zu

7 Joseph Müller-Blattau, „Die musikalischen Schätze der Staats- und Universitätsbibliothek zu Königsberg i. Preußen “, in ZfMw 6 (I924), S. 2 I 5-239, hier vor allem S. 219-228.

8 Das Bassus-Stimmbuch Berlin, Geheimes Staatsarchiv Preußischer Kulturbesitz MS 7 ist eine der wenigen erhaltenen Musikalien aus der herzoglichen Musikbibliothek, die später in die Staats- und Universitätsbibliothek Königsberg integriert wurde. Zum vollständigen Manuskript siehe Eckhard Loge, Eine Messen- und Motettenhandschrift des Kantors Matthias Krüger aus der Musikbibliothek Herzog Albrechts von Preussen, Kassel I93 I, sowie neuerdings Anna Dieleman, Berlin, Geheimes Staatsarchiv Preussischer Kulturbesitz MS 7: Codicological, Textual and Contextual Aspects of a Mid-Sixteenth-Century Prussian Music Manuscript, Masterarbeit Universität Utrecht 2009, eine Arbeit, die jedoch kritisch gelesen werden muss. Die restlichen Stimmbücher sind seit dem Zweiten Weltkrieg verschollen. Reproduktionen der Stimmbücher Discant, Tenor und Vagans haben sich jedoch erhalten und befinden sich heute im Staatlichen Institut für Musikforschung Berlin unter der Signatur No Fot 230, I-2 (Discant); No Fot 230, 5-6 (Tenor) und No Fot 230, 8 (Bassus, fol. 88 $8^{\mathrm{v}}-\mathrm{I}^{\mathrm{r}} \mathrm{I}^{\mathrm{r}}$; Vagans).

9 Hierin schreibt Walther: „Gnediger Herr / Ich hab von etzlichen offtmals vorstandenn / wie E. F. G. Zur Musica / vnd gesang grosse gunst vnd lust tragen ..." Eine Edition zweier Briefe Walthers ist bereits seit längerer Zeit zugänglich in Moritz Fürstenau, ,Johann Walther, kurfürstlich sächsischer Kapellmeister. Eine biographische Skizze“, in $A m Z$ N.F. I (I863), Sp. 242-25I, Sp. 262-267, Sp. 282-286. Der Verbleib der insgesamt drei Briefe von Johann Walther an Herzog Albrecht war nach dem Zweiten Weltkrieg bislang unbekannt. Alle drei Dokumente befinden sich heute im Geheimen Staatsarchiv Preußischer Kulturbesitz in Berlin. Der betreffende Brief vom 6. Februar I 526 wird unter der Signatur XX, HA, HBA, A4, Kasten I82, AZ 3.36.4. verwahrt. Ein fünfstimmiges Lied mit dem obigen Titel ist von Johann Walther nicht überliefert. Gleichwohl findet sich in der Ausgabe des Gesangbüchleins von I 544 (Nr. 55) und I 55 I (Nr. 60) das Lied Johanns Ernst bin ich getauft für fünf Stimmen mit dem Akrostichon ,Johanns Ernst Herzog zu Sachsen“. Eine spätere Umdichtung wäre denkbar, muss jedoch Spekulation bleiben. Johann Walter, Sämtliche Werke, Bd. I: Geistliches Gesangbüchlein, Wittenberg 1551, Erster Teil: Deutsche Gesänge, hrsg. von Otto Schröder, Kassel u.a. I953, S. Iogf. Die anderen an Herzog Albrecht übersandten Lieder, können aufgrund der zahlreichen Möglichkeiten nicht identifiziert werden.

IO „Dann worynn ich E F. G. Es seÿ mit liedern machen / oder anderem gesang Zugefallen dienen kan / will ich gegen E. F. G. als ey[n] eygener diener bereÿtt seÿn.“ 
lassen, sowohl nach dessen Konvertierung (I 525 ) als auch in dem für den sächsischen Hof nicht unbedeutenden Jahr I 545. In einem Brief vom I 8. Januar I $545^{\text {II }}$ übersandte er ihm „,ii exemplar eines VII stimmigen gesangs dem heiligen lieben evangelio und dem Churfürsten zu Sachsen zu ehren gestellet und sunst ein clein deutsch liedlein von dem Jungsten tage auf ein alte Melodey ...". Da Walther in Ermangelung einer Antwort von Seiten des Herzogs am 7. September I 545 seinen siebenstimmigen Gesang noch einmal nach Königsberg schickt und nun eindeutig von einer gedruckten Motette spricht, ${ }^{12}$ handelt es sich bei dem groß besetzten Werk um die fünfteilige Motette Beati immaculati (Ps. I I9), die Walther für die Einweihung der Torgauer Schlosskapelle (5. Oktober I 544) komponiert hatte. ${ }^{13}$ Durch die noch im selben Jahr I 544 erfolgte Veröffentlichung als Einzeldruck bei Georg Rhau in Wittenberg ${ }^{\mathrm{I}}$ erhält die Motette nicht nur einen äußerst exklusiven Nimbus, sie steht auch durch und durch in lutherischem Kontext, hatte Martin Luther doch selbst die Kapelle eingeweiht und zu diesem Anlass auch gepredigt. Durch alle fünf partes hindurch ist die Motette über einen vierfach kanonisch geführten Tenor (Kanon in unisono) konstruiert. Die Bassstimme singt über dem Intervall $c-g$ den Text „Viue Luthere, Viue Melanthon [!], | Viuite nostræ Lumina terræ, | Charaq[ue] Christo Pectora, per uos, | Incly-

I I Berlin, Geheimes Staatsarchiv Preußischer Kulturbesitz, XX, HA, HBA, A4, Kasten 2I3, A.Z.3.36.5. (I.), ediert in Fürstenau, „Johann Walther“, Sp. 25 of.

I2 Berlin, Geheimes Staatsarchiv Preußischer Kulturbesitz, XX, HA, HBA, A4, Kasten 2I4, A.Z.3.36.5. (II.). Walther spricht von einem "gedruckten psalm sieben stymmig / vnd sunst auch drey newe geschriebne gestuck funff vnd vierstymmig "Stücke. Bereits im Januar I 545 vermerkt Walther, dass ihm der Herzog nicht geantwortet hätte. Ob sich dies auf den ersten Brief von I 526 oder ein unlängst geschicktes Schreiben bezieht, ist derzeit zwar nicht feststellbar, doch auch in diesem dritten Brief ist die Enttäuschung über das Schweigen Albrechts deutlich bemerkbar. Für eine Übertragung dieses bislang bei Fürstenau, ,Johann Walther“, nur in Fußnote von Sp. 25 I zitierten dritten Briefes siehe Anhang 2.

I3 Die Identifizierung des im Oktober ebenfalls nach Königsberg versandten „clein deutsch liedlein von dem Jungsten tage auf ein alte Melodey ... “ist dagegen schwieriger. Wenngleich eine Drucklegung erst sehr spät erfolgte, wäre hier vielleicht doch Walthers Herzlich tut mich erfreuen denkbar. Einzeldruck Wittenberg: Georg Rhaus Erben I 552, nur Altus und Bassus erhalten: Ein schöner Geistlicher und Christlicher neuer Berckreyen, von dem Jüngsten tage, und ewigem Leben, auff die Melodey und weise, Hertzlich thut mich erfreuen, etc. Mit einer neuen Melodey gezieret (RISM W 175). Edition in Johann Walter, Sämtliche Werke, Bd. 3: Lieder und Motetten, die nur 1524, 1525 und 1544 im Wittenbergischen Gesangbüchlein enthalten oder in Handschriften und Drucken verstreut sind, hrsg. von Otto Schröder und Max Schneider, Kassel u.a. I955, S. 73.

I4 RISM W I74. Edition in Johann Walter, Sämtliche Werke, Bd. 5: Cantiones septem vocum (1544). 1545, Magnificat octo tonorum ... Jenae 1557, hrsg. von Otto Schröder und Max Schneider, Kassel u.a. I96I, mit Faksimile des Tenortitelblattes sowie einiger weiterer Seiten auf S. I09-I I I. Vgl. auch Jürgen Heidrich, „Bemerkungen zu den Psalmkompositionen Johann Walters. Über humanistische Züge im nichtliturgischen Schaffen des, protestantischen Urkantors““, in Johann-Walter-Studien. Tagungsbericht Torgau 1996, hrsg. von Friedhelm Brusniak, Tutzing I998, S. I I 8 sowie I22f. sowie die dort in Fn. 34 angegebene Literatur. 
ta nobis Dogmata Christi, | Reddita: Vestro Munere, pulsis: | Nubibus atris: Prodijt ortu, | Candidiore Dogma salutis, | Viuite longos Nestoris annos. Amen.“, während die Altstimme auf dem Ton $g^{\mathrm{I}}$ repetierend einen Preistext auf Kurfürst Johann Friedrich I. von Sachsen („der Großmütige“) rezitiert. ${ }^{\text {IS }}$

Ebenfalls unmittelbar nach Jahresbeginn I 526 erhielt Albrecht in Stoltzers bekanntem Brief vom 23. Februar die beiden Psalmmotetten Noli aemulari, 6v. (Ps. 37) ${ }^{16}$ und Exaltabo te (Ps. I I 8), erstere in einer Übersetzung von Martin Luther, letztere in lateinischer Sprache. ${ }^{17}$ Beide Vertonungen haben einen unterschiedlichen Kompositionsanlass und unterscheiden sich in der inhaltlichen wie intentionalen Ausrichtung: Dass es sich bei Erzürn dich nicht nicht um eine zufällige Vertonung hält, bezeugt Stoltzer wenn er schreibt, dass es seine „allergnädigste fraw" (Maria von Ungarn) war, die ihn mit der Vertonung dieses Psalms in einer Übersetzung von Martin Luther beauftragt hatte; über die heute verlorene lateinische Psalmvertonung Exaltabo te vermerkt Stoltzer jedoch, dass er den Text „auß sunderem Lust zu den überschönen worten gesetzt“ hätte. Könnte bei der monumentalen Motette von Ps. 37 (sieben Partes, 584 Mensuren) auf die zahlreichen Schwierigkeiten angespielt werden, mit denen sich Albrecht gerade in den Anfangszeiten der Reformation im ehemaligen Gebiet des deutschen Ordens konfrontiert sah und die I532 schließlich zur Reichsacht führten, so werden bei der verlorenen Komposition weniger die liturgische Verwendbarkeit im Gottesdienst, als vielmehr das Interesse an der eigentlichen Textaussage und das Offenbarwerden einer persönlichen Ästhetik in den Vordergrund gerückt. ${ }^{18}$

I5 „Viuat Viuat Viuat. Viuat Ioannes Friderich: | Elector \& Dux Saxonum: | Defensor ueri dogmatis: | Pacisq[ue] custos peruigil: | Viuat per omne seculum. Amen.“

I6 Edition in Thomas Stoltzer, Ausgewählte Werke, Zweiter Teil: Sämtliche Psalmmotetten, hrsg. von Lothar Hoffmann-Erbrecht, Frankfurt I969 (EdM 66/7), S. I 28-I 55.

I7 Stoltzer weist in diesem Brief stolz darauf hin, dass der Psalm zum ersten Mal überhaupt „motettisch“ gesetzt worden wäre und merkt an, dass er den Satz so komponiert hätte, dass er vollständig mit Krummhörnern zu spielen wäre. Der Brief ist bereits erwähnt bei Voigt, „Deutsche Musik im I6. Jahrhundert“ (wie Anm. 2), S. 2 I0. Eine vollständige Edition findet sich bei Eitner, „Briefe von Thomas Stoltzer, Adrian Rauch und Silvester Raid“ (wie Anm. 5), hier S. 67 sowie bei Lothar Hoffmann-Erbrecht, Thomas Stoltzer: Leben und Schaffen, Kassel I964 (Die Musik im alten und neuen Europa 5), S. 33-36, Faksimile auf Tafel II. Für eine erste Bewertung der sechsstimmigen Psalmmotette siehe Otto Kade, „Thomas Stoltzer's Psalm: Noli aemulari, 6 vocum. Ein kunstgeschichtlicher Beitrag“, in MfM 8 (I876), S. I33-I48, I49-I55, I77-202; Karl-Ludwig Hampe, „Über zwei deutsche Psalmen von Thomas Stoltzers [!]“, in Musik des Ostens I, Kassel I962, S. I46-I 58; sowie Hoffmann-Erbrecht, Thomas Stoltzer, S. I22-I26. Eine Einsichtnahme in Karl-Ludwig Hampe, Die deutschen Psalmen des Thomas Stoltzer, Diss. Univ. Posen I 943 war mir leider nicht möglich.

I8 Siehe hierzu auch Ludwig Finscher, ,,auss sunderrem lust zu den überschönen worten“. Zur Psalmkomposition bei Josquin Desprez und seinen Zeitgenossen“, in Literatur, Musik und Kunst im Übergang vom Mittelalter zur Neuzeit. Bericht über Kolloquien der Kommission zur Erforschung der Kultur des Spätmittelalters 1989 bis 1992, hrsg. von Hartmut Boockmann u.a., Göttin- 
Neben diesen, von außen an den Hof herangetragenen Musikalien, versuchte Albrecht auch selbst unermüdlich eine Hofmusik auf- und den Königsberger Hof zu einem kulturellen Zentrum auszubauen. ${ }^{19}$ Dies beinhaltete nicht nur die Akquisition verschiedenster Musikalien, sondern auch die Anstellung verschie-

gen I995 (Abhandlungen der Akademie der Wissenschaften in Göttingen, PhilologischHistorische Klasse, Dritte Folge, Nr. 208), S. 246-26I.

I9 Obwohl durch die Arbeiten von Federmann, Ruhnke, Finscher u.a. bereits zahlreiche Details zum Hof in Königsberg bekannt geworden sind, würde eine systematische Aufarbeitung mit Hilfe der heutigen zunehmend institutionalisierten Forschung noch viele Einzelheiten ans Tageslicht bringen. Diese kann hier freilich nicht erfolgen. Festzuhalten bleibt, dass Albrecht bis zu seinem Tod nicht müde wurde, den Repertoirebestand seiner Hofmusik umfassend zu erweitern, u.a. auch mit dem Ankauf von Nachlässen verstorbener Musiker (Paul Tschackert, Urkundenbuch zur Reformationsgeschichte des Herzogthums Preußen, hrsg. von dems., Neudruck der Ausgabe I890, Osnabrück I965 [Publicationen aus den K. Preußischen Staatsarchiven 2], Nr. I096, Nr. I097, jeweils S. 360 und die Nr. I I09, I I I0, S. 365 f.). In einem Brief vom 30. Januar I 543 (Berlin, Geheimes Staatsarchiv Preußischer Kulturbesitz, XX, HBA, A4, Kasten 209, A.Z.3.36.7; Edition Eitner, „Zwei Briefe von Georg Wytzel“ [wie Anm. 5], S. I 57-I 59, hier S. I 58 und Bente, Neue Wege [wie Anm. 4], S. 347f.) bezieht sich der Nürnberger Georg Wyltzel (Wilzel) auf eine Übersendung von selbst kopierten Stücken, für die er auf herzogliche Anweisung ein silbernes Trinkgeschirr erhalten hatte; er bedankt sich hierfür und übersendet weiter „etliche gutte wolgestelte Stuck von Messen vnd Mutteten (die mir von etlichenn kauffleuten, auf mein anlangen aus den welschen vnd Niderlande ist new vnd nit gemein zugestelt) genotirt“. Derselbe Wyltzel übersendet im Dezember I 549 eine Messe, „die ein Burger und kauffmann alhie, ein Synger und sonderlicher libhaber der Musick, zu Venedig auff sein Namen und kosten, durch ein berümpten Componisten, Pyrison genant, machen und setzen lassen, und sonst nyemandt bekannt, sampt etlichen Muteten und Lydern ... zur furstlichen Hochzeit zur freud habe zugebrauchen “. Die Messe stammt von Cambio Perissone, einem Sänger und Komponisten an San Marco in Venedig, dessen geistliche Musik bis auf die Motette $A d$ te Domine in RISM I $549^{7}$ vollständig verloren scheint (vgl. James Haar, Art. „Perissone, Cambio“, in New Grove 2 , Bd. I9, S. 436f.). Wyltzel übersendet die Messe wie auch die übrigen Werke zur bevorstehenden Hochzeit des Herzogs mit Prinzessin Anna Maria von Braunschweig-Calenberg am 26. Februar I550. Zu weiteren Akquisitionsaktivitäten Herzog Albrechts siehe Voigt, „Deutsche Musik im I6. Jahrhundert“ (wie Anm. 2), S. 2 I 3 f., Müller-Blattau, „Die musikalischen Schätze“ (wie Anm. 7), passim, wie auch umfassend Maria Federmann, Musik und Musikpflege zur Zeit Herzog Albrechts, Kassel 1932 (Königsberger Studien zur Musikwissenschaft I4), S. I 48-I 52.

Albrecht ließ sich aber nicht nur Musik sondern auch Bücher schicken. Den in Freundschaft verbundenen Maler Lucas Cranach, der in Wittenberg in den I $520 e r$ Jahren eine eigene Offizin unterhielt, bittet er am 29. September I 526, dass er ihm „alle neue gute leswürdige Bücher, so in kurzem bei euch oder andern wären ausgegangen ... kaufen und aufs fürderlichste herein übersenden. Die wollen wir allenthalben gerne bezahlen etc." Tschackert, Urkundenbuch, Nr. 5I6, S. I75. Cranach übersandte die gewünschten Bücher I527, musste aber zweimal wegen der vollständigen Begleichung der Rechnung nachfragen, da ihm nur ein Teil des ausstehenden Betrages ausbezahlt worden war. Tschackert, Urkundenbuch, Nr. 62 I, S. 2 I 2 f. und Nr. 664, S. 225. 
dener Musiker. ${ }^{20}$ Dass ihm das durchaus gelang und er auf seine Hofmusik stolz war, zeigt der Brief vom 22. November I535, in dem er Ludwig Senfl eine Komposition vom Preußischen Hof überschickt, ${ }^{21}$ und ein Schreiben an Martin Luther vom 3I. März I 537, worin er diesem drei Motetten von Hans Kugelmann zukommen lässt, darunter zwei Psalmvertonungen. ${ }^{22}$

Obwohl die Korrespondenz mit Senfl I 526 beginnt, intensiviert sich der Briefkontakt nicht vor den I530er Jahren, und erst nach einem Brief Senfls vom I. August I 534 beginnt sich schließlich ab September I 534 eine mehr oder weniger regelmäßige Kommunikation zwischen den beiden Männern und vor allem Lukas Wagenrieder zu entwickeln. ${ }^{23}$ Der erste der erhaltenen Briefe datiert jedoch aus dem Jahr I 528 und thematisiert einen Satz von sechs schwarz gebundenen Stimmbüchern mit sechs-, fünf- und vierstimmigen Motetten, die Senfl I 526 an Albrecht geschickt haben muss. ${ }^{24}$ Senfl und der Herzog dürften bereits seit längerer Zeit miteinander bekannt gewesen und sich möglicherweise schon auf dem Augsburger Reichstag I 5 I 8 begegnet sein. In der freien Reichsstadt hielten sich von Juli bis Mitte Oktober dieses Jahres nicht nur Kaiser Maximilian I. mit seiner Hofkapelle, sondern auch zahlreiche weltliche und geistliche Fürsten des

20 Zum Status und zur Entwicklung der Hofkapelle siehe vor allem Federmann, Musik und Musikpflege, passim; sowie die letztere korrigierend und ergänzend Martin Ruhnke, Beiträge zu einer Geschichte der deutschen Hofmusikkollegien im 16. Jahrhundert, Berlin I963, S. I38-I47; darüber hinaus auch Ludwig Finscher, „Beiträge zur Geschichte der Königsberger Hofkapelle“, in Musik des Ostens I, Kassel u.a. I962, S. I65-189.

2 I,$\ldots$ so vberschickenn wir euch hiemit ein geschickt dinng, sampt deselbenn Composition, daraus Ihr zuersehenn, wes dennocht auch in diesenn weitgelegenenn Landenn vnnd vhast in der Wiltnus vonn Componistenn sein ...“. Berlin, Geheimes Staatsarchiv Preußischer Kulturbesitz, XX, Ostpreußische Folianten Nr. 27, S. 339-340; Edition bei Bente, Neue Wege (wie Anm. 4), S. 33 of.

$22, \ldots$ Wyr uberschicken euch hiemit ein lied, welchs der erwirdig, unser freundt, rath und lieber getreuer her Paulus Speratus, bischof zu Pomezan, vom concilio, deßgleichen zwen psalmen, den I2I. welchen wir, und den 39., welchen unser componiste Hans Kugelman alhie gemacht und neben den anderen componirt, genediglich begerende, ir wollet diß alles, euerem hohen von Got verliehenem verstandt und geschickligkeit nach, corrigiren, bessern und mehren und uns dergleichen auch bißwehlen zuschicken und mitteilen ...", Text zitiert nach der Edition in Paul Tschackert, „Kleine Beiträge zu Luthers Leben“, in Theologische Studien und Kritiken 62 (I889), S. 359-378, hier S. 375-377. Tschackert, Urkundenbuch (wie Anm. I9), Nr. I082, S. 355 .

23 Der bislang letzte Brief Wagenrieders datiert vom I4. Februar I 54I. Für eine Transkription siehe Anhang 3 .

24 Berlin, Geheimes Staatsarchiv Preußischer Kulturbesitz, XX, HBA, A4, Kasten I84, 29.I.I 528. Edition in DTB III/2 (wie Anm. 3), S. LVIII und Bente, Neue Wege, S. 3 I 2f. (Die dortige Nennung einer Edition bei Fürstenau, „Ludwig Senfl und Markgraf Albrecht“, S. 565 ist nicht korrekt.) 
Heiligen Römischen Reiches auf. Neben der brennenden Frage eines Türkenfeldzuges, dem Verhör Martin Luthers durch den päpstlichen Legaten Kardinal Thomas Cajetan (I2.-I4. Oktober) und dem Versuch Maximilians I., die Nachfolge seines Enkels Karls V. zu sichern ${ }^{25}$ abgesehen also von diesen theologisch und politisch brisanten Geschäften, wurde am 25. August ein Ereignis von besonderem gesellschaftlichen Interesse gefeiert: die Hochzeit von Kasimir, Markgraf von Brandenburg-Ansbach mit Susanna von Bayern. Dabei ließ es sich der Kaiser, dessen Sänger die Messe gestalteten, nicht nehmen, seine Nichte Susanna - sie war die Tochter seiner Schwester Kunigunde, und Schwester der Bayernherzöge Wilhelm IV., Ludwig X. und Ernst - persönlich zum Altar zu führen. ${ }^{26}$

Wie Birgit Lodes vermutet, hatte Senfl, der als inoffizieller Hofkomponist des Kaisers wohl auch für den musikalischen Rahmen des Gottesdienstes verantwortlich gewesen sein wird, für diese Hochzeit wahrscheinlich seine im Liber Selectarum Cantionum (RISM I $520^{4}$ ) enthaltene Motette Beati omnes (i) komponiert, einen Psalm, der zur Augsburger Hochzeitsliturgie gehörte. ${ }^{27} \mathrm{Zu}$ Senfls musikalischem „Output“ für die Hochzeit von Kasimir und Susanna könnten aber noch andere Werke gehören, wobei eines davon ein Satz mit dem Textincipit Capitan Herr Gott darstellen könnte. Das Neuburger Kapellinventar von I 544 (D-HEu Cod. Pal. Germ. 3 I 8) verzeichnet zwei bislang verschollene vierstim-

25 Kaiser Maximilian schloss mit den Kurfürsten ein geheimes Wahlabkommen, das Karl die Krone sichern sollte. Hermann Wiesflecker, Kaiser Maximilian I.: das Reich, Österreich und Europa an der Wende zur Neuzeit, Bd. 4: Gründung des habsburgischen Weltreiches, Lebensabend und Tod, 1508-1519, Wien I98 I, S. 396 sowie umfassend S. 404-4I 5.

26 Die Chroniken der schwäbischen Städte, Bd. 4: Augsburg, Leipzig I 894 (Die Chroniken der deutschen Städte 23), darin Die Chronik von Clemens Sender von den ältesten Zeiten der Stadt bis zum Jahre 1536, mit der Beschreibung des Reichstages auf den S. I35-I44, die Hochzeit auf S. I 4of. $\mathrm{Zu}$ den komplexen Vorverhandlungen siehe Katrin Nina Marth, Die dynastische Politik des Hauses Bayern an der Wende vom Spätmittelalter zur Neuzeit „Dem löblichen Hawss Beirn zu pesserung, aufnemung vnd erweiterung ...", Diss. Universität Regensburg 2009, S. 32I-335. Zu den Hochzeitsfeierlichkeiten siehe Wiesflecker, Kaiser Maximilian I., S. 390-392; siehe auBerdem Gerhard Pietzsch, „Die Beschreibungen deutscher Fürstenhochzeiten von der Mitte des I5. bis zum Beginn des I7. Jahrhunderts als musikgeschichtliche Quelle“, in Anuario $\mathbf{M u -}$ sical I5 (1960), S. 2 I-62, hier S. 35f. Die ausführliche Hochzeitsbeschreibung bei Johann Haslberger, Die Stend des hailigen Roemischen Reichs, ... so zu Augspurg ... auff dem yetzuerganngen, loblichen Reichstag erschinen ..., Augsburg: [Silvanus Otmar] I5 8 (Abdruck bei Ulrich Hutteni equitis germani opera quœ reperiri potuerunt omnia, hrsg. von Eduard Böcking, Bd. 5, Leipzig I 86I, S. 28 I-299). Der offizielle Reichstagsabschied erfolgte am I4. Oktober. Maximilian I., und mit ihm wohl auch die Hofkapelle, hatte jedoch bereits am 23. September die Stadt verlassen. Wiesflecker, Kaiser Maximilian I., S. 392.

27 Birgit Lodes, „Zu Ludwig Senfls Josquin-Rezeption“, Vortrag gehalten bei der Tagung Josquin Des Prez - Ein unbeschreibliches Genie?, Bremen Io./I I. Juni 20IO. Ich danke Birgit Lodes herzlich für die Überlassung des Vortragsmanuskriptes. 
mige Sätze Senfls mit diesem Textbeginn $;^{28}$ und tatsächlich lassen sich zwei mögliche und zudem eng miteinander verwandte Kandidaten in $\mathrm{D}-\mathrm{Mu} 8^{\circ} \mathrm{Cod}$. ms. $328-33 \mathrm{I}^{29}$ und in B-Br II. 3843 finden. ${ }^{30}$ Mit Ausnahme der vier eröffnenden Brevispausen in D-Mu $8^{\circ}$ Cod. ms. 328-33 I stimmen die Tenores beider Sätze hinsichtlich des Textincipits, als auch im Hinblick auf den rhythmischen und melodischen Verlauf völlig überein und bilden somit eine Werkfamilie „en miniature“. Die Zusammengehörigkeit der beiden Sätze ist zudem durch den in beiden Quellen überlieferten Text gegeben. Dieser verwendet den Namen des Bräutigams, „CaSiMir MarckGraf Zw BranDenBourgk“, ${ }^{\text {I }}$ als Akrostichon, ein Umstand, der sich in mehreren Hochzeitsliedern Senfls in den Jahren um I 520 nachweisen lässt.

Der in B-Br II.3843 niedergeschriebene Satz weist zwar nicht die in der Neuburger Quelle verzeichnete Vierstimmigkeit auf sondern ist fünfstimmig konzipiert, doch ähnelt dies der Vorgehensweise bei zahlreichen anderen in dieser Handschrift enthaltenen Lieder, die ursprünglich nur für vier Stimmen komponiert und erst für die Anfertigung der Stimmbücher mit einer zusätzlichen fünften Stimme versehen worden sind. Im vorliegenden Fall scheint der Vagans in der Brüsseler Quelle hinzukomponiert zu sein. Er ist in keiner besonderen Weise in das übrige Satzgeschehen involviert und hat nur eine klangstützende Funktion. Dazu tendiert der Bassus des fünfstimmigen Satzes zwar auch, doch bildet der Bassus meist die tiefste Stimme und kann im Gefüge einer angedeuteten Imitation im Gegensatz zum Vagans nicht weggelassen werden (siehe die Übertragung in Notenbsp. I).

28 Vergleiche fol. I I $6^{\mathrm{r}}$ des unter $<$ http://digi.ub.uni-heidelberg.de/diglit/cpg3 I $8>$ einsehbaren Digitalisates.

29 Fol. $\mathrm{I} 5^{\mathrm{v}}-\mathrm{I} 7^{\mathrm{r}}$ des Tenorstimmbuches, der einzigen erhaltenen Stimme dieser Komposition. Die von Clytus Gottwald, Die Musikhandschriften der Universitätsbibliothek München, Wiesbaden I968 (Die Handschriften der Universitätsbibliothek München 2), S. 84 vorgenommene Autorzuweisung an Lupus Hellinck ist nicht gerechtfertigt, der Tenor ist anonym überliefert.

30 Discant: fol. IO ${ }^{\mathrm{r}}-{ }^{\mathrm{v}}$; Alt: fol. $\mathrm{IO}^{\mathrm{v}}-\mathrm{II}^{\mathrm{r}}$; Tenor: fol. $43^{\mathrm{r}}-47^{\mathrm{v}}$; Bass: $\mathrm{IO}^{\mathrm{v}}-\mathrm{II}^{\mathrm{r}}$; Vagans: fol. $\mathrm{IO}^{\mathrm{v}}-\mathrm{II}^{\mathrm{r}}$.

3 I Der vollständige Text bei Philipp Wackernagel, Das deutsche Kirchenlied von der ältesten Zeit bis zu Anfang des XVII. Jahrhunderts, 3. Bd., Leipzig I850, Nr. I 54, S. I I6f. 
Stefan Gasch
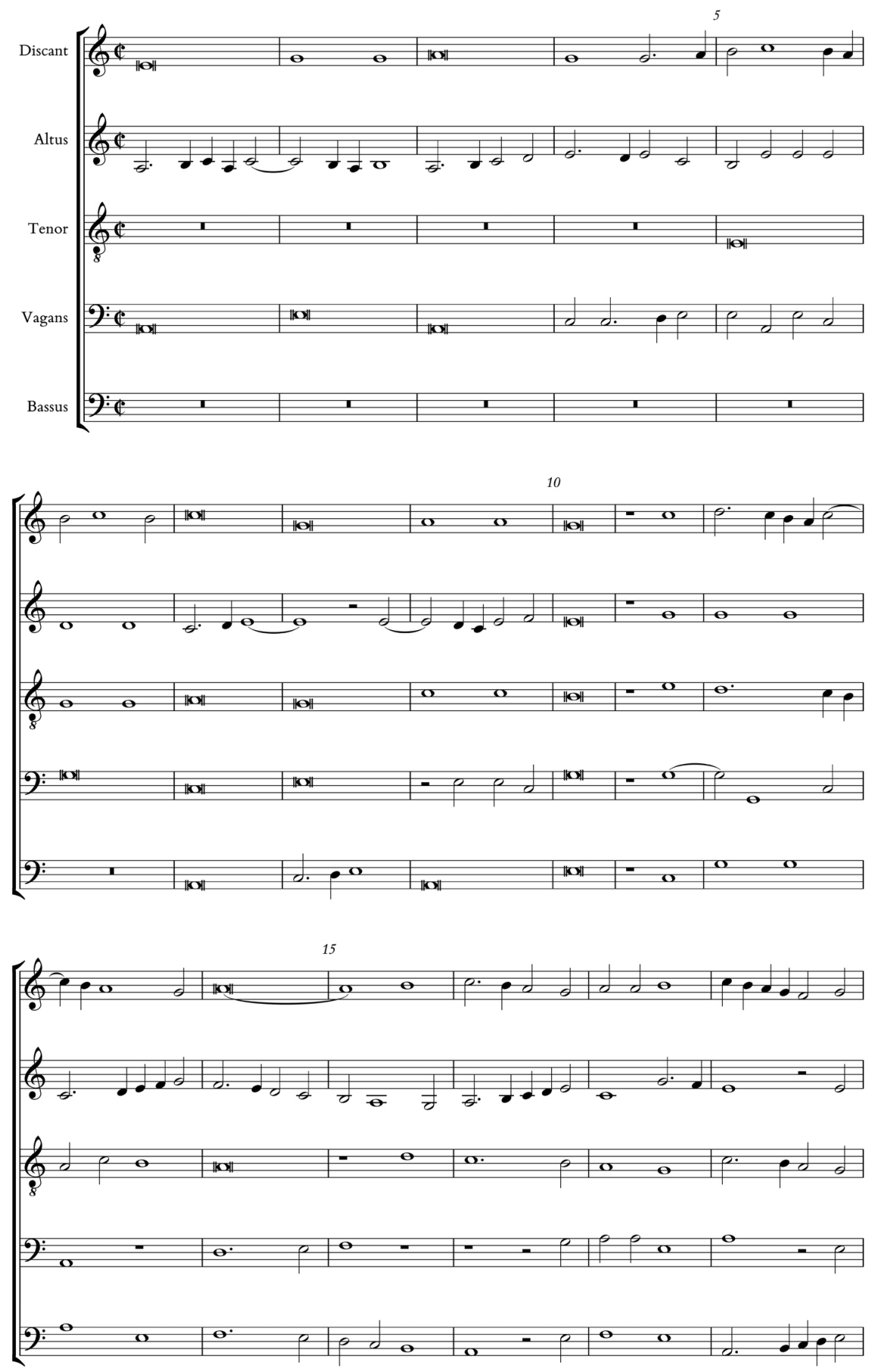

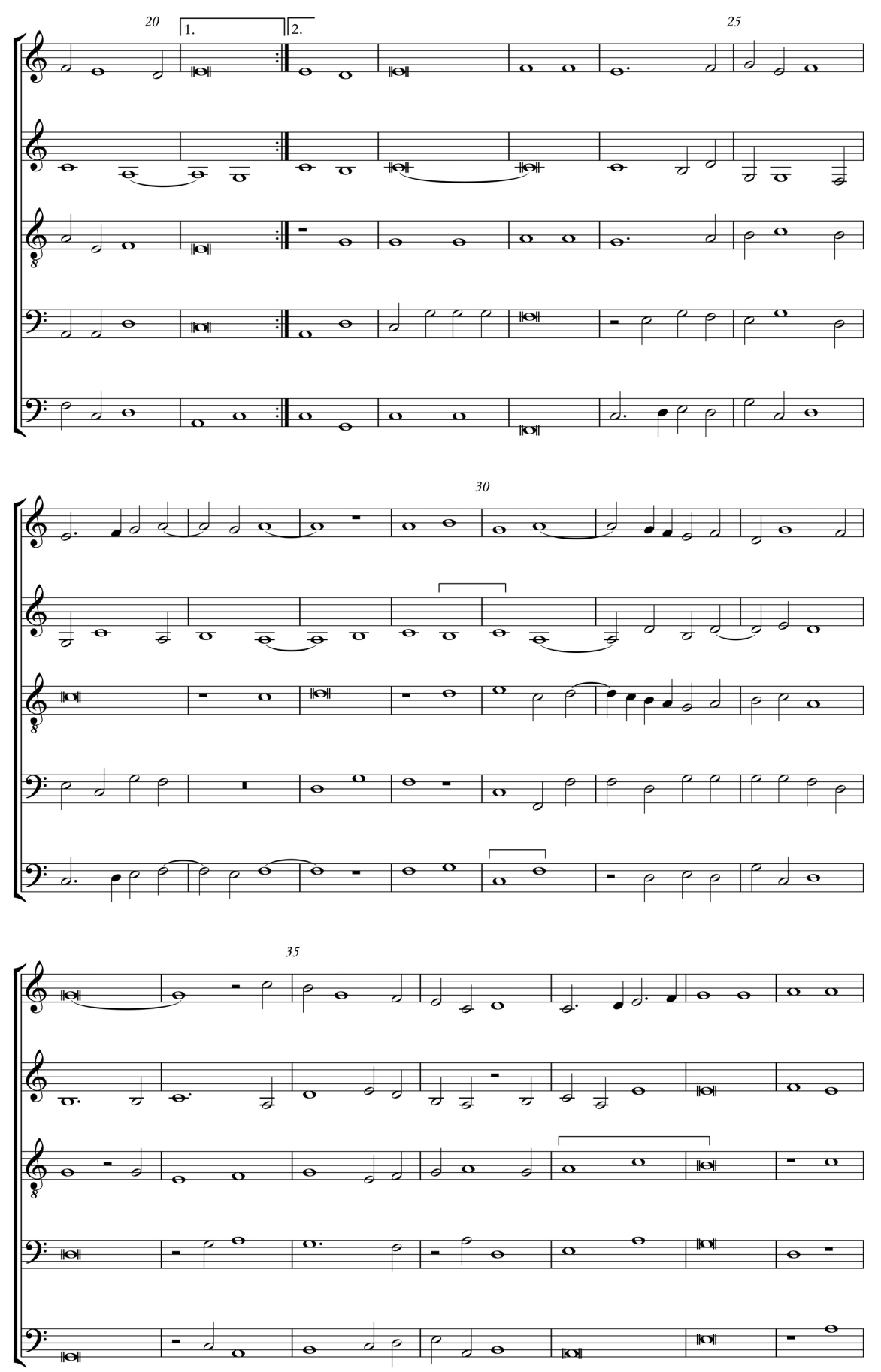


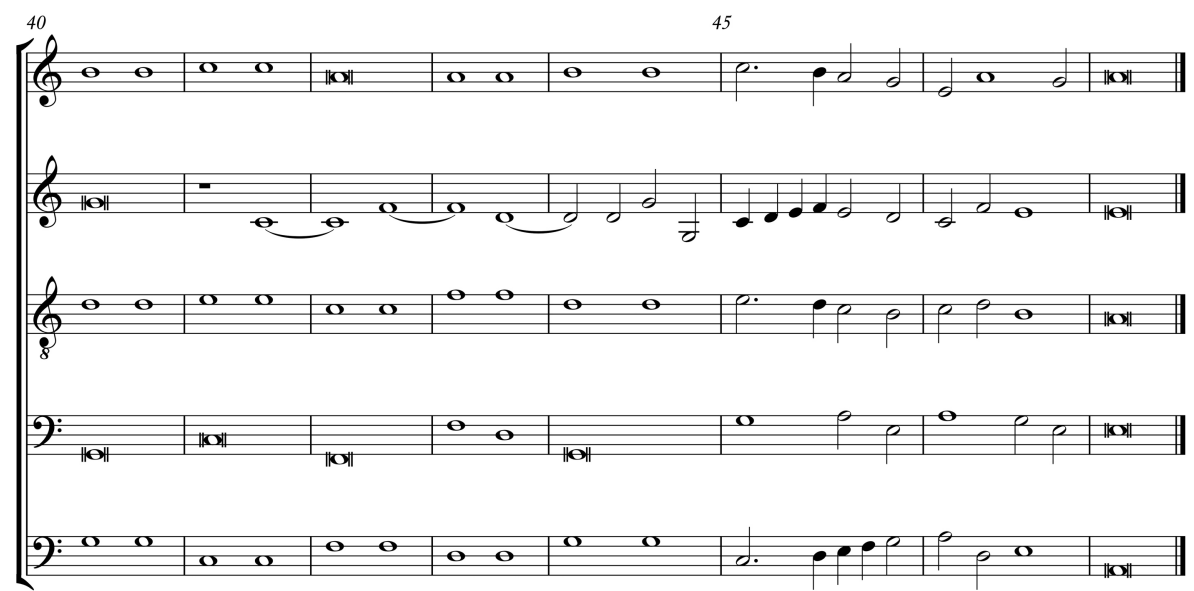

Notenbsp. I : Anonym, Capitan Herr Gott Vater mein, B-Br II.3843, Nr. I2

Mit Blick auf die übrigen mehrstimmigen Vertonungen dieser Tenormelodie ${ }^{32}$ steht vor allem die Frage nach der Autorschaft Lupus Hellincks im Raum. Der Tenor seines Satzes ${ }^{33}$ ähnelt nicht nur sehr stark dem Tenorverlauf der beiden Sätze in Brüssel und München, wie D-Mu $8^{\circ}$ Cod. ms. 328-33 I eröffnet Hellincks Satz darüber hinaus ebenfalls ohne Brevispausen. Im Unterschied zu den beiden anderen Liedern ist die Tenormelodie bei Hellinck aber sowohl bei der Textstelle „Vater mein/ dein“ (M. Iof.) als auch bei „die stund ist hie“ (M. 2730) ohne Semibrevispause komponiert. Wäre dies noch kein eindeutiges Indiz gegen Hellincks Autorschaft, so ließe sich als ein weiteres Argument das Textincipit der Sätze in Brüssel und München anführen, das Auswirkungen auf den mehrstimmigen Satz hat. Während der Tenor des anonymen Satzes in B-Br II.3843 der Silbenzahl des Wortlautes Capitan Herr Gott Vater mein genau folgt und mit einer überraschenden Generalpause in Mensur I I umsetzt, ${ }^{34}$ vertont der überlieferte Hellinck'sche Satz die Worte Capitan Herre Gott Vater mein und muss bei der Textstelle „Herre“ die Melodie in zwei Semibreven aufbrechen (M. 7). Darüber hinaus versucht er an dieser Stelle vielmehr die nachfolgenden Verszeilen zusammenzuziehen. Im Unterschied zu Hellinck stellt somit der anonyme

32 Anonymer Satz in RISM I $544^{20}$, Nr. I09; anonymer Satz in D-GRu Mss. BW 640-64I (nur Diskant und Bass erhalten).

33 CH-Bu F X 21, Nr. 4; RISM I $544^{20}$, Nr. 67; RISM I $544^{21}$, Nr. I IO. Eine Edition findet sich in Newe Deudsche Geistliche Gesenge für die Gemeinen Schulen, gedrückt zu Wittemberg / durch Georgen Rhau 1544, hrsg. von Johannes Wolf, Leipzig I 908 (DDT I/34), S. I68f.

34 Über den Münchner Satz lassen sich aufgrund des rudimentären Überlieferungszustandes keine weiteren Aussagen machen. 
Brüsseler Satz devisenartig den Titel des Liedes vor, was durchaus dem Entstehungshintergrund des Liedes geschuldet sein könnte.

Sollte also der in B-Br II.3843 aufgezeichnete Capitan-Satz ein Werk Senfls für das Brautpaar sein, so fände sich das entsprechende Pendant für die Braut in Senfls Lied So Glück und Stund' mit dem Akrostichon „SoSaNa“ im ersten Abschnitt der Handschrift D-Mbs Mus.ms. 3 I $55 .{ }^{35}$ Nicht nur hat Nicole Schwindt nachgewiesen, ${ }^{36}$ dass sich in diesem Abschnitt zahlreiche konkrete Bezüge zum Augsburger Reichstag von I5 18, zu Maximilian I. und schließlich zu Senfl niederschlagen, dieser Teil der Handschrift also mithin in der Reichsstadt selbst angefertigt worden sein dürfte; darüber hinaus lässt sich - wie im Capitan-Satz von B-Br II.3843 - auch in diesem Lied die Herangehensweise beobachten, den Text der ersten Verszeile mittels einer Generalpause vom restlichen Satz abzuheben, ein Verfahren, das Senfl nur in drei weiteren Liedern mit Akrostichon anwendet: E. schön und zart (Senfl, $S W \mathrm{~V}, \mathrm{Nr}$. 34), bei dem die jeweils zusammengehörenden ersten beiden Verszeilen von Generalpausen umschlossen sind; Lust mag mein Herz (Senfl, SW II, Nr. 8) mit einer Generalpause nach der ersten Verszeile, sowie der Satz Mag ich Unglück nit widerstan (Senfl, $S W$ V, Nr. I3), bei dem, dem Prinzip von So Glück und Stund' folgend, sowohl die erste Verszeile als auch die sich anschließende Textinsel mittels einer Generalpause vom Text abgetrennt werden. ${ }^{37}$

Hingewiesen sei auch auf den auffälligen Überlieferungskontext des Brüsseler Satzes, der die Vermutung von Senfls Autorschaft für diesen Satz weiter stützt:

35 Fol. $37^{\mathrm{v}}-38^{\mathrm{r}}$. Das Lied ist darüber hinaus auch in CH-Bu F X I-4 (Diskant: fol. $47^{\mathrm{v}}$, Alt: fol. $48^{v}$, Tenor: $74^{v}$, Bassus: $47^{v}$ ) überliefert. Den Hinweis auf das Lied verdanke ich Sonja Tröster, der ich an dieser Stelle nochmals herzlich für die ausführlichen Diskussionen danke.

36 Nicole Schwindt, „Der Text zu einem bisher textlosen Lied Ludwig Senfls“, in Mf 63 (20I0), S. 257-264, sowie deren Vortrag „Senfl und das Manuskript München 3 I 55 “ bei der Tagung Senfl in Zürich, Zürich, 26./27. März 2010.

37 Für eine vollständige Zusammenstellung der Senfl'schen Liedsätze mit Akrostichon siehe die Übersicht im Beitrag von Sonja Tröster im vorliegenden Band. 
Stefan Gasch

Tabelle I: Kompositionen mit Akrostichon in B-Br II. $3843^{3^{8}}$

\begin{tabular}{l|l|l|l|l} 
NR. & AKROSTICHON & TITELTRÄGER & LIEDINCIPIT & KOMPONIST \\
\hline 2 & $\begin{array}{l}\text { FriDeReÿch König } \\
\text { Zw DenMerch }\end{array}$ & $\begin{array}{l}\text { Friedrich I., König von } \\
\text { Dänemark († I 533) }\end{array}$ & $\begin{array}{l}\text { Frid gib vns lieber } \\
\text { herre }\end{array}$ & anon. \\
\hline 3 & $\begin{array}{l}\text { SoPhiA Königin CZW } \\
\text { DenMargk }\end{array}$ & $\begin{array}{l}\text { Sophia von Pommern; } \\
\text { zweite Gattin Friedrichs }(\dagger \\
\text { I 568); Hochzeit: 9. Okto- } \\
\text { ber I5 I 8 }\end{array}$ & $\begin{array}{l}\text { Sol ich her vor dir } \\
\text { bestan }\end{array}$ & anon. \\
\hline 4 & $\begin{array}{l}\text { Von Gottes Gnad } \\
\text { ChristiAn König In } \\
\text { Denmargken }\end{array}$ & $\begin{array}{l}\text { Christian III., König von } \\
\text { Dänemark († I 559); Sohn } \\
\text { aus erster Ehe }\end{array}$ & $\begin{array}{l}\text { Von gottes gnad, } \\
\text { rat vnd wunderthat }\end{array}$ & {$[\text { M. Kugelmann }]^{40}$} \\
\hline 6 & MaRiA & Maria von Ungarn? & $\begin{array}{l}\text { Mas zucht } \\
\text { verstandt }\end{array}$ & {$[\text { L. Senfl }]^{41}$} \\
\hline 7 & MaRiA ${ }^{42}$ & Maria von Ungarn & $\begin{array}{l}\text { Mag ich vnglukh } \\
\text { nit widerstan }\end{array}$ & {$[\text { L. Senfl }]^{43}$}
\end{tabular}

38 Die Akrostichen erscheinen ausnahmslos in den im Tenor wiedergegebenen Texten. Die übrigen Stimmen tragen wenn überhaupt nur ein Textincipit.

39 Darüber hinaus auch am Ende jeder Strophe die Abkürzung „A.G.S.D.W.“. Es handelt sich hier sowohl um eine Abkürzung des Strophenrefrains „Ach Gott schaff Deinen Willen“ als auch die Devise König Christians III. Hans Rupprich, Die deutsche Literatur vom späten Mittelalter bis zum Barock, München 1973 (Geschichte der deutschen Literatur von den Anfängen bis zur Gegenwart IV/2), S. 239. Im Mai I 545 übersendet der Hoftrompeter Jörg/Georg Hayd (Jørgen Heyde) mehrere Sätze des ebenfalls am Dänischen Hof in Kopenhagen angestellten Jørgen Presten nach Königsberg, darunter auch Ach Herr sehe uns gnaedig an, das ebenfalls Christians Motto als Refrain, zusätzlich aber auch als Akrostichon verarbeitet. Margaret Munck, Art. „Presten, Jørgen“, in New Grove, Bd. 20, S. 304f., John Bergsagel, Art. „Presten, Jørgen“, in $M G G^{2}$, Personenteil Bd. I3, Kassel u.a. 2005, Sp. 9 I $8 f$.

40 Konkordanz: Ettliche Teutsche Liedlein, Geistlich und Weltlich, mit Drey, Vier, Fünff unnd Sechs stimmen, auf alle Instrument zugebrauchen, Königsbgerg: Johann Daubmann, I 558 [Widmung: I 560]. RISM K 2968, Nr. 6 mit Autorzuweisung. Da mir die Einsichtnahme in das einzig erhaltene Exemplar (PL-Tm Ms. I02680 [olim J $4^{\circ}$ 29-32]) nicht möglich war, erfolgen diese Konkordanzangaben nach Henrik Glahn, „En ny kilde til belysning af det preussiske hofkapels repertoire på Hertug Albrechts tid“, in Svensk Tidskrift för Musikforskning 43 (I96I), S. I45-I6I. Zum handschriftlichen Anhang des Druckes siehe neuerdings Agnieszka Leszczyńska, „The Königsberg Manuscript from the Kugelmann Circle“, in Journal of the Alamire Foundation 2 (2010), S. 52-66.

4I Konkordanz: RISM I $539^{27}$, Nr. I I I. Vagans hinzukomponiert; in D-Mbs Mus.ms. 3 I 55 mit einem Vagans ergänzt, dieser ist jedoch nicht identisch mit dem Vorliegenden.

42 Die Aufnahme dieser beiden Lieder ist auffällig. Zwar war der Bruder Albrechts, Georg von Brandenburg-Ansbach, Erzieher von Marias Mann, dem späteren König Ludwig II. von Ungarn und Böhmen, doch Maria von Ungarn gehörte nicht zum engeren Kreis der beiden Hoffamilien. Da es keinen weiteren Hinweis auf die Identifizierung der in Lied-Nr. 6 genannten „Maria“ mit der Königin von Ungarn und Böhmen gibt, bleibt Glahns Annahme fraglich. Glahn, „En ny kilde“ (wie Anm. 40), S. I48.

43 Konkordanz: RISM I $539^{27}$, Nr. I02. Vagans hinzukomponiert. Zum Kontext dieses Liedes siehe auch den Beitrag von Sonja Tröster in diesem Band. 
Ludwig Senfl, Herzog Albrecht und der Kelch des Heils

\begin{tabular}{|c|c|c|c|c|}
\hline 8 & $\begin{array}{l}\text { Von Gotts Gnad } \\
\text { AlBrecht MargkGraff } \\
\text { Zw BranDenBorg } \\
\text { HärtZugk In Preussen }\end{array}$ & $\begin{array}{l}\text { Hzg. Albrecht von Bran- } \\
\text { denburg-Preußen } \\
(† \text { I } 568)\end{array}$ & $\begin{array}{l}\text { Von Menschen her, } \\
\text { ist nie erhört } \\
\text { Zusatz: F. Dht. } \\
\text { In preussen lied: }\end{array}$ & anon. ${ }^{44}$ \\
\hline 9 & $\begin{array}{l}\text { Von Gottes Genaden } \\
\text { DoroTheA Herzogin } \\
\text { In Preussen }\end{array}$ & $\begin{array}{l}\text { Dorothea von Dänemark, } \\
\text { erste Gattin Hzg. Albrechts } \\
(† \text { I } 546)\end{array}$ & $\begin{array}{l}\text { Von got dem herren } \\
\text { haben whir } \\
\text { Zusatz: Meiner } \\
\text { gnädigisten: F: In } \\
\text { preussen } \\
\text { Zusatz in Bassus } \\
\text { (notiert im Va- } \\
\text { gans): F: dht In } \\
\text { preussen gemalh } \\
\text { lied }\end{array}$ & {$[\text { M. Kugelmann }]^{45}$} \\
\hline IO & $\begin{array}{l}\text { Devise „Ich trau zu } \\
\text { Got:“" }\end{array}$ & $?$ & Ich trau zu Got: & {$[\mathrm{M} . \text { Kugelmann }]^{46}$} \\
\hline II & $\begin{array}{l}\text { Von Gottes Gnad } \\
\text { AnNa SophiA Ein } \\
\text { Freülein In Preussen }\end{array}$ & $\begin{array}{l}\text { Anna Sophia, erste Tochter } \\
\text { Hzg. Albrechts ( }{ }^{\star} \text { I 527) }\end{array}$ & $\begin{array}{l}\text { Von gottes gnad, } \\
\text { mein seel die hat } \\
\text { (nur T vorhan- } \\
\text { den) }\end{array}$ & {$[\text { M. Kugelmann }]^{47}$} \\
\hline I2 & $\begin{array}{l}\text { CaSiMir MarckGraf } \\
\text { Zw BranDenBuo[r]gk }\end{array}$ & $\begin{array}{l}\text { Kasimir von Brandenburg- } \\
\text { Kulmbach, ältester Bruder } \\
\text { Hzg. Albrechts († I 527) }\end{array}$ & $\begin{array}{l}\text { Capitan herr Got } \\
\text { vatter mein }\end{array}$ & anon. (L. Senfl?) \\
\hline I 4 & $\begin{array}{l}\text { WilHelm MarGraff } \\
\text { Cw BranDenBurgk }\end{array}$ & $\begin{array}{l}\text { Wilhelm von Brandenburg- } \\
\text { Ansbach (I } 498-\text { I563), } \\
\text { Bruder Hzg. Albrechts, } \\
\text { Erzbischof von Riga, Hzg. } \\
\text { von Livland }\end{array}$ & $\begin{array}{l}\text { Wil got mein wher } \\
\text { und waffen sein }\end{array}$ & anon. \\
\hline I5 & ErnWil TräutHalm & $?$ & Ernwert auff erdt & anon..$^{8}$ \\
\hline I 8 & $\begin{array}{l}\text { nur Devise „Alles in } \\
\text { Ehren kann niemand } \\
\text { wehren“ }\end{array}$ & $\begin{array}{l}\text { Johann Friedrich I. („,der } \\
\text { Großmütige“), Kurfürst } \\
\text { von Sachsen (I } 503-\mathrm{I} 554) \\
\end{array}$ & $\begin{array}{l}\text { Forma decens / Als } \\
\text { in ehrenn }\end{array}$ & A. Willaert ${ }^{49}$ \\
\hline
\end{tabular}

44 Konkordanz: DK-Kk Ms. Gamle Kongelige Samling I 872, $4^{\circ}$.

45 Konkordanzen: DK-Kk Ms. Gamle Kongelige Samling I872, $4^{\circ}$; RISM K 2968, Nr. 5, mit Autorzuweisung.

46 Konkordanz: RISM K 2968, Nr. 4, mit Autorzuweisung.

47 Konkordanz: RISM K 2968, Nr. 20, mit Autorzuweisung.

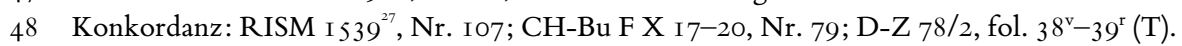

49 Konkordanz: DK-Kk Ms. Gamle Kongelige Samling I 872, $4^{\circ}$. Discant, Alt und Bassus singen Forma decens, der Tenor die Devise als ostinato. 
Die fünf Stimmbücher dieser für Prinzessin Dorothea (seit I 526 Gattin Herzog Albrechts von Brandenburg-Preußen) $)^{50}$ wahrscheinlich am elterlichen Hof in Dänemark angefertigten Handschrift, ${ }^{51}$ enthalten überwiegend geistliche Lieder, darunter mehrere Werke Senfls, zwei weitere Lieder davon mit Akrostichen. Diese Lieder bilden mit mehreren anderen Kompositionen dieser Handschrift ein Programm, bei dem die durch Heirat verbundenen Höfe von Dänemark und Preußen anhand von Liedern mit Akrostichen präsentiert werden: Auf dem Augsburger Reichstag von I 5 I 8 wäre es Ludwig Senfl aber auch möglich gewesen Kontakte zu anderen Personen zu knüpfen: mit Martin Luther, der wie Ulrich von Hutten ebenfalls im Haus Konrad Peutingers ein- und ausging, ${ }^{52}$ mit Herzog Wilhelm IV. von Bayern, darüber hinaus aber eben auch mit Herzog Albrecht von Brandenburg-Preußen, ${ }^{53}$ der sich zur Hochzeit seines älteren Bruders Kasimir ebenfalls in der Reichsstadt aufhielt.

Da Albrecht am I. Juli I 526 Prinzessin Dorothea, Tochter König Frederiks I. von Dänemark, heiratete, könnten die Stimmbücher mit sechs-, fünf- und vierstimmigen Motetten, auf die Albrechts Kanzler Michael Spilberger ${ }^{54}$ I 528 in seinem Brief an Senfl anspielt und die Albrecht I526 von Senfl erhalten hatte, ein Hochzeitsgeschenk darstellen, für das sich Albrecht mit „22 preussisch ellen damast" bedanken wollte. Diese Annahme wird nicht zuletzt dadurch erhärtet, dass Spilberger die Zeitangabe „anderthalb Jar vngeferlich vergangen“ erwähnt und somit den Sommer I 526 als Lieferdatum der Bücher angibt. Weil Senfl aber auch nach weiteren vier Jahren noch nichts von diesem Geschenk gesehen hatte, hakte er zwar am I. August I 532 noch einmal persönlich nach, aber er sollte noch einige Zeit auf das zugesagte Gegengeschenk warten müssen.

50 Die Hochzeit, für die sich der Bruder des Herzogs, Casimir, wegen des Reichstages in Speyer entschuldigte, dauerte vom I.-4. Juli I 526. Christoph von Gattenhofen, Bericht über die Vermählung des Herzogs Albrecht mit der Prinzessin Dorothea, in Tschackert, Urkundenbuch (wie Anm. I9), Nr. 49I, S. I65 sowie Nr. 498, S. I67-I70. Laut Tschackert, Urkundenbuch, Nr. 499, S. I 70 wurde auch eine Schaumünze mit dem Hochzeitspaar geprägt.

5 I Eine erste Beschreibung und Auswertung der Quelle findet sich bei Henrik Glahn, „En ny kilde" (wie Anm. 40).

52 Vgl. Bente, Neue Wege (wie Anm. 4), S. 287-289.

53 Senfl muss nicht zwingend durch Luther mit Albrecht bekannt gemacht worden sein wie Kroyer in DTB III/2 (wie Anm. 3), S. LVII vermutet (ebenso Müller-Blattau, „Die Musikalischen Schätze“ (wie Anm. 7), hier S. 226). Albrecht war allein deswegen schon in Augsburg (siehe Clemens Senders Chronik [wie Anm. 24], S. I 38), weil die deutschen Fürsten gemeinsam aufgerufen waren die vom Papst nachgesuchte Türkensteuer zu verweigern. Tschackert, Urkundenbuch (wie Anm. I9), S. 5 f.

54 Spilberger war am 6. Februar I 523 zum Kanzler Herzog Albrechts berufen worden. Tschackert, Urkundenbuch, Nr. 94, S. 24. 
Trotz des umfangreich dokumentierten Austausches lassen sich die Werke, die Senfl als Auftragskompositionen von Seiten des Herzogs oder aus eigenem Willen nach Königsberg geschickt hatte, nur in Einzelfällen identifizieren. Unter den deutschen Liedern sind es zunächst die drei vierstimmigen und ohne Text überlieferten Sätze Dem ewigen Gott, Albrecht, mir's schwer und In Lieb und Freud, von denen allgemein angenommen wird, dass sie zum übersandten Liedrepertoire gehörten. Vor allem die Nennung des Namens „Albrecht“ im zweiten Lied hat Hans-Joachim Moser zu dieser Annahme bewogen. ${ }^{55}$ Martin Bente folgte dieser Annahme, äußerte aufgrund mehrerer Begleitumstände im Zusammenhang mit der Überlieferung aber auch den Verdacht der Bestimmung einer gröBeren Liedgruppe für Königsberg: ${ }^{56}$ Zum einen liegen für die Lieder Dem ewigen Gott und In Lieb und Freud Parallelvertonungen von Hans Kugelmann vor, dem Kapellmeister Herzog Albrechts; zum anderen bilden diese drei Lieder eine eigene geschlossene Einheit (Nr. 83-85) in der einzigen Quelle A-Wn Mus.Hs. I 88 Iо, ähnlich dem ebenfalls hier überlieferten von Senfl stammenden FortunaZyklus (Nr. 70-73) ) $^{57}$ und dem Liedzyklus mit dem kontrafazierten Liedtenor Kein Adler in der Welt (Nr. 77-80). Zusätzlich zu diesen Liedeinheiten nimmt Bente auch die Lieferung der Lieder Nr. $74-76,{ }^{58} \mathrm{Nr} .8 \mathrm{I}-82^{59}$ sowie das Quodlibet Nr. $86^{60}$ für Albrecht an. Bente bringt allerdings keine zwingenden Nachweise für eine „königsberger" Bestimmung der letztgenannten Lieder; meist genügt ihm die singuläre Überlieferungssituation der Liedsätze und so bleibt unklar, warum Werke wie N'a vous point veu mal assenée sowie Walthers Satz des Luther-Liedes Nun bitten wir den heiligen Geist (5v.) von Senfl für den Hof in Königsberg bestimmt gewesen wären. Zwar tragen bekanntlich drei der vier Lieder des Fortuna-Zyklus Datumsvermerke für den September des Jahres I 533 (Nasci, pati, mori/Fortuna,${ }^{61}$ Helena desiderio/Fortuna, ${ }^{62}$ und Virgo prudentissima/Fortuna $\left.{ }^{63}\right)$,

55 Hans Joachim Moser, „Instrumentalismen bei Ludwig Senfl“, in Festschrift für Johannes Wolf zu seinem sechzigsten Geburtstage, hrsg. von Walter Lott, Helmuth Osthoff und Werner Wolffheim, Berlin I929, S. I23-I27, hier S. I24. Moser spekuliert sogar über die Textanfänge der üblicherweise dreistrophigen Hofweise.

56 Bente, Neue Wege (wie Anm. 4), S. 267 bzw. S. 327.

57 Die Nummerierung in dieser Wiener Handschrift erfolgt nach Rainer Birkendorf, Der Codex Pernner. Quellenkundliche Studien zu einer Musikhandschrift des frühen 16. Jahrhunderts (Regensburg, Bischöfliche Zentralbibliothek, Sammlung Proske, Ms. C 120), Augsburg 1994 (Collectanea Musicologica 6), Bd. 3, S. I65-I67.

58 L. Senfl: Die Brünnlein die da fließen (6v.); Le Brun: N'a vous point veu mal assenée; L. Senfl: Wahrhaftig mag ich sprechen wohl (4v.; auch in RISM I $534^{17}$ ).

59 Nr. 82 signiert mit „Conradus Rupsch d.J.“, Satz jedoch von Johann Walther: Nun bitt wir den heiligen Geist; L. Senfl: Ohn' allen Scherz (4v.).

60 L. Senfl: Ach Gott wem soll ich klagen/Ich armer Mann/Mein Herz ist alles Traurens voll (5v.).

6I Discant, fol. $42^{\mathrm{v}}$ : „,2 I. sept. $33^{\prime \prime}$. 
die als Hinweise einer Lieferung von Musikalien von München nach Königsberg gedeutet werden können, und in der Tat schreibt Albrecht im September I 534: „Wir habenn die Tenor so Ihr vnns vor einem Jahr zugeschickt zu genedigem dencklichem gefallenn empfangenn, ..." ${ }^{64}$ Letztlich kann jedoch nur für die Nummern 83-85 (aufgrund des Inhalts) und den Fortuna-Zyklus (aufgrund der beigefügten Jahreszahlen) plausibel gemacht werden, dass sie zu jener Lieferung gehörten, die Senfl bereits I 533 (oder vorher) nach Preußen geschickt hatte.

Die beiden anderen Lieder, die in den Briefen Wagenrieders vom 4. August I 537 namentlich erwähnt werden, das „padlied“ und „die dreyerlay hofweis mit 6.5.vnd 4“, konnten mit Senfls Im Bad wöll wir recht fröhlich sein (4v.) und dessen Vertonungen von Wiewohl viel herter Örden sind à $4 \mathrm{v}$., à $5 \mathrm{v}$. und à $6 \mathrm{v}$. (RISM I $544^{20}$, Nr. 66, 99, I I 4$)^{65}$ identifiziert werden. Ersteres hat sich in keiner Quelle aus Senfls Lebzeit erhalten und ist nur im dritten Teil von Georg Forsters Liedersammlung (RISM I $549^{37}$, Nr. 23) überliefert, die letzteren drei Sätze hatte Senfl noch ein zweites Mal in eigenhändiger Kopie am 2. August via Georg Schultheis nach Königsberg geschickt. ${ }^{66}$

Darüber hinaus dürfte Albrecht auch Senfls sechsstimmiges Quodlibet Kein Adler in der Welt so schön/Es taget vor dem Walde/Ich stuend an einem Morgen gekannt und möglicherweise sogar besessen haben. In seinem Brief an den Herzog vom

62 Discant, fol. $44^{\mathrm{r}}:, 28$. septe[m]b[ris]. Anno d[omi]ni. I $533^{\prime \prime}$.

63 Discant, fol. $45^{\mathrm{v}}$ : „Anno dni I 533 primo Octobris“.

64 Sperrung vom Autor.

65 Ludwig Senfl, Sämtliche Werke, Bd. V: Deutsche Lieder zu vier bis sechs Stimmen, 3. Teil: Lieder aus den gedruckten Liederbüchern von Egenolf 1535, Finck 1536, Schöffer und Apiarius 1536, Forster 1530-1540, Salblinger 1540 und Ott 1544, hrsg. von Arnold Geering und Wilhelm Altwegg, Wolfenbüttel I949, Nr. 49, 57, 65. Die Identifizierung (nicht zuletzt aufgrund Wagenrieders Bemerkung, dass er die elf Strophen nur dem vierstimmigen Satz beigegeben hätte) findet sich bereits bei Kroyer in DTB III/2 (wie Anm. 3), S. XLVII, Anm. 2 sowie S. LXIVff. (Kroyer liest fälschlicherweise „par lied“.) Die vierstimmige Fassung des Satzes in D-Mbs Mus.ms. 3 I 55 bzw. CH-Bu F X I-4 (Senfl, SW, Bd. II: Deutsche Lieder zu vier bis sechs Stimmen, I. Teil: Lieder aus handschriftlichen Quellen, hrsg. von Arnold Geering und Wilhelm Altwegg, Wolfenbüttel/Zürich I962, Nr. 24) ist dagegen nicht gemeint, zumal diese über eine andere Tenormelodie gearbeitet ist und ohne weitere fünf- und sechsstimmige Fassungen auftritt.

66 Brief Senfls vom 2. August I 538 (Berlin, Geheimes Staatsarchiv Preußischer Kulturbesitz, XX, HBA, A4, Kasten I99, I 538 VIII 2): „...vnd hiemit Schikh ich Euch ein Copej die Ich mit aigner hannd geschrieben hab, die wellet hochgedachtem Meinem gnedigisten Herrn. herr[e]n Albrechten In preissen hertzogen etc. In Ir f g. Selbhannden antwurten. Dabej Ir f.g. drej Composition der lieder so ich f.g. zu vnnd[er]=thenigem geuallen Componiret hab auf die hoffweis, die herr lucaß. Iren $\mathrm{f} g$. geschriben.“ 
5. November I $539^{67}$ schickt Silvester Raid eine anonyme fünfstimmige Komposition Kein Adler in der Welt/Es taget vor dem Walde und weist Albrecht darauf hin, dass bereits mehrere Komponisten derartige Sätze verfasst hätten, darunter Adrian Willaert und Ludwig Senfl. ${ }^{68}$ Auch die Überlieferungssituation würde in das bisher bekannte Bild passen: Neben dem Abdruck in RISM I $544^{20}$ (Nr. 5) ist das Lied in DK-Kk Ms. Gamle kongelige Samling I872, $4^{\circ}$ tradiert, einer Quelle, die ein weiteres Bindeglied zwischen den Höfen Dänemarks und Preußens darstellt: Sie wurde vermutlich von Albrechts ehemaligem Trompeter Jörg/Georg Hayd (Jørgen Heyde) angefertigt ${ }^{69}$ und präsentiert mehrere Widmungskanons für die Familienoberhäupter König Christian III. von Dänemark, Herzog Albrecht von Preußen, Herzog Heinrich von Braunschweig und Kurfürst Johann Friedrich I. von Sachsen („,der Großmütige“).$^{70}$

Hinsichtlich der „... drey Tenor sonnderlich vnnser Person betreffende ...“, die Albrecht in seinem Brief vom I6. September I $534^{71}$ übersandt hatte um sie mehrstimmig setzen zu lassen, und die Senfl am i5. Mai I 535 mittels Johann Apel zustellen ließ, muss die Antwort weiterhin offen bleiben. Denkbar wäre etwa die Bitte um eine mehrstimmige Vertonung der Akrostichon-Lieder für die drei Herzogsbrüder Kasimir, ${ }^{72}$ Georg $^{73}$ und Albrecht, oder Vertonungen von eigenen Texten des Herzogs. Vorerst muss dies jedoch Spekulation bleiben.

Senfls Teu'r, Hoch, Erleucht't (4v.) wiederum, für das Arnold Geering und Wilhelm Altwegg, ${ }^{74}$ diesen folgend auch Wilhelm Seidel ${ }^{75}$ eine Bestimmung für den preußischen Herzog sahen, muss nicht zwingend für Königsberg kompo-

„Auch hieneben ein stuckh kain Adler darein geschlossen, es taget vor dem walde haben viel hochberiembter Componisten alls Adrianus Willart mit andern alls Ludwicus Sennfl, sover ... die Namen E. F. G. hievor mochten furkomen sein, ir Composition daruber gemacht mit 6. 5. 4 und 3. stimmen, wie in dieser Composition mit fünff anzaigt wirdt." Zitiert nach Eitner, „Briefe von Thomas Stoltzer, Adrian Rauch und Silvester Raid“ (wie Anm. 5), S. 69.

$68 \mathrm{Zu}$ einer möglichen Identifizierung siehe die Tabelle im Anhang.

69 Als solcher ist er I 535 am Königsberger Hof nachweisbar. Ruhnke, Hofmusikkollegien (wie Anm. 20), S. I4I. Zu dessen Austausch mit Königsberg siehe auch oben Fn. 35. Eine umfassende Studie zum Musikalien-Austausch zwischen den beiden Höfen unter Einbeziehung dieser Handschriften steht noch immer aus.

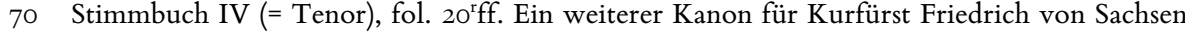
in Stimmbuch VI.

7I Berlin, Geheimes Staatsarchiv Preußischer Kulturbesitz, XX, Ostpreußische Folianten Nr. 27, S. I68-I69; Edition in Bente, Neue Wege (wie Anm. 4), S. 327.

$72 \mathrm{Zu}$ Capitan Herre Gott siehe die Ausführungen weiter oben sowie Tabelle I.

73 Genad mir, Herr, ewiger Gott. Philipp Wackernagel, Das deutsche Kirchenlied von der ältesten Zeit bis zu Anfang des XVII. Jahrhunderts, Bd. 3, Leipzig I870, Nr. I 55.

74 Senfl, $S W$ II, S. I43.

75 Wilhelm Seidel, Die Lieder Ludwig Senfls, Bern 1969 (Neue Heidelberger Studien zur Musikwissenschaft 2) S. I3 8 f. 
niert worden sein. Die Bitte um einen ausstehenden Lohn wie ihn Senfl I 532 erwartete, scheint mehr als „in höfisch verblümter Weise“ und sehr indirekt vorgetragen zu werden; ebenso muss der aus der Namensbedeutung abgeleitete Textbeginn nicht notwendigerweise auf Albrecht bezogen sein. ${ }^{76}$

Unter den zahlreichen Motetten, die ihren Weg nach Königsberg fanden, sind namentlich nur sechs in den Briefen Wagenrieders genannt. Darunter findet sich Senfls große, wohl für den Augsburger Reichstag I 530 entstandene Psalmmotette Ecce quam bonum (4v.). ${ }^{77}$ Wagenrieder erwähnt die Motette in seinem „Beschwerdebrief" vom 9. Februar I536, nachdem Senfl mit einem goldenen Trinkgeschirr bezahlt worden wäre, er selbst aber nicht entlohnt worden war. Er vermerkt, dass er den Psalm bereits „vber 2 iar mer“ nach Königsberg gesandt hätte, womit der Zeitpunkt der Niederschrift bzw. Überbringung nach Preußen gegen Ende des Jahres I 533 (zusammen mit den Fortuna-Liedern?) oder an den Anfang des Jahres I 534 fällt.

Weitere von Wagenrieder erwähnte Werke sind die jeweils fünfstimmigen Sätze Vita in ligno, Qui prophetice prompsisti und Qui expansis in cruce (Brief vom Mai I 537). Dabei handelt es sich nicht um separate Motetten, sondern um die drei zusammengehörenden Partes einer fünfstimmigen Motette, die nicht zuletzt aufgrund von Formschneiders/Otts Novum et insigne opus musicum (RISM I 537 zu den am weitesten verbreiteten und beliebtesten Kompositionen in Senfls gesamten Motettenschaffens gehört und in nicht weniger als 35 Quellen überliefert wird, mehr als die Hälfte davon in Tabulaturen (Tabelle 2).

76 Die Annahme von Rebecca Wagner Oettinger, dass Senfl die Lieder O du armer Judas, Ein'n $A b t$, den wöll wir weihen sowie Mag ich Unglück nit widerstan an Albrecht gesandt hätte, entbehrt eines stichhaltigen Nachweises. Rebecca Wagner Oettinger, „Ludwig Senfl and the Judas Trope: Composition and Religious Toleration at the Bavarian Court", in EMH 20 (200I), S. I99-225, hier S. 215. Die dort ohne Seitenzahl angegebene Belegstelle bei Bente, Neue Wege (wie Anm. 4) ist nicht nachvollziehbar.

77 Bente, Neue Wege, S. 333. 
Tabelle 2: Überlieferung der Motette

Qui prophetice prompsisti- Qui expansis in cruce - Vita in ligno (5v.) von Ludwig Senfl ${ }^{78}$

\begin{tabular}{|c|c|}
\hline HANDSCHRIFTEN & REIHENFOLGE DER EINZELNEN PARTES \\
\hline CH-Sk Ms. 87-4 & nur 3.p. \\
\hline CZ-ROk A V 22 & $? 79$ \\
\hline $\begin{array}{l}\text { D-B Sammlung Bohn Ms. mus. } 8 \\
\text { (olim Breslau, Stadtbibliothek) }\end{array}$ & 3.p. - I.p. $-2 \cdot p$. \\
\hline $\begin{array}{l}\text { D-B Sammlung Bohn Ms. mus. I I } \\
\text { (olim Breslau, Stadtbibliothek) }\end{array}$ & 3.p. - I.p. - 2.p. \\
\hline D-Dl Mus. Glashütte 5 & 3.p. - I.p. - 2.p. ${ }^{80}$ \\
\hline D-Dl Mus. Grimma 56 & nur 3.p. \\
\hline D-Dl Mus. Grimma 57 & nur 3.p. \\
\hline D-Dl Mus. Löbau 8 / Löb 70 & 3.p. - I.p. - 2.p. \\
\hline D-Lr Mus. Ant. Pract. K.N. I 50 & 3.p. - I.p. $-2 \cdot$.p. \\
\hline D-LÜh Mus. A 203 & $?^{8 \mathrm{I}}$ \\
\hline D-Mbs Mus.ms. IO & I.p. $-2 . p .-3 \cdot p$. \\
\hline D-Mu 327 & nur T der 3.p. \\
\hline D-Sl Mus. fol. I 43 & I.p. $-2 \cdot$.p. $-3 \cdot$.p. \\
\hline H-Bn Ms. mus. Bártfa 2 & nur 3.p. \\
\hline
\end{tabular}

DRUCKE

\begin{tabular}{|c|c|}
\hline RISM I $537^{\mathrm{I}}$ & 3.p. - I.p. - 2.p. \\
\hline RISM I $559^{1}$ & 3.p. - I.p. - 2.p. \\
\hline
\end{tabular}

THEORETISCHE SCHRIFTEN

Eucharius Hofman, Musicae practicae praecepta communiora ... (Wittenberg: Schwertel I 572$)^{82}$ dominus factus est obediens, die mit „Quarta pars Vita in ligno“ überschrieben ist, weder bekannt ist, ob es sich um einen möglichen weiteren Teil dieser Motette handelt, noch eine Autorzuweisung gegeben ist, wird diese Komposition hier nicht berücksichtigt. Eine liturgische Zusammengehörigkeit ist aber durchaus gegeben.

79 Quelle konnte nicht eingesehen werden.

80 Quelle aufgrund des schlechten Erhaltungszustandes nicht benützbar.

8I Quelle konnte nicht eingesehen werden. 
LAUTENTABULATUREN (HANDSCHRIFTEN)

\begin{tabular}{l|l}
\hline D-B Mus. ms. 40 632 & $\begin{array}{l}\text { fol. }{ }^{\mathrm{I}} 3^{\mathrm{v}}-\mathrm{I} 4^{\mathrm{r}}(3 \cdot \mathrm{p} .), \\
\text { fol. } 29^{\mathrm{v}}-3 \mathrm{I}^{\mathrm{r}}(\mathrm{I} \cdot \mathrm{p} \cdot-2 . p .)\end{array}$ \\
\hline D-Lr Ms. Mus. ant. pract. I I96 & 3.p. - I.p. - 2.p. \\
\hline D-Mbs Mus.ms. 267 & 3.p. - I.p. - 2.p. \\
\hline D-Mbs Mus.ms. 272 & nur 3.p. \\
\hline F-Pn Rés 429 & 3.p. - I.p. - 2.p. \\
\hline PL-Kj Mus. ms. 40598 & nur 3.p. \\
\hline
\end{tabular}

LAUTENTABULATUREN (DRUCKE)

\begin{tabular}{l|l}
\hline Brown I $544_{3}$ & 3.p. - I.p. $-2 . p$. \\
\hline Brown I $547_{3}$ & nur 3.p. \\
\hline Brown I $549_{6}$ & 3.p. - I.p. - 2.p. \\
\hline Brown I $558_{5}$ & nur 3.p. \\
\hline Brown I $574_{5}$ & 3.p. - i.p. - -2.p. \\
\hline
\end{tabular}

TABULATUREN F. TASTENINSTRUMENTE (HANDSCHRIFTEN)

\begin{tabular}{l|l}
\hline D-B Sammlung Bohn Ms. mus. I8 & 3.p. - I.p. $-2 . p$. \\
\hline D-B Sammlung Bohn Ms. mus. I I9 & 3.p. - I.p. - 2.p. \\
\hline PL-Kp Ms. I7I6 & nur 3.p. \\
\hline PL-Wn rkp. 564 & zwei Fassungen, jedoch jeweils nur 3.p. \\
\hline
\end{tabular}

TABULATUREN F. TASTENINSTRUMENTE (DRUCKE)

\begin{tabular}{l|l}
\hline Brown I $583_{4}$ & 3.p. - I.p. $-2 . p$. \\
\hline Brown I $583_{6}$ & 3.p. - I.p. $-2 . p$. \\
\hline
\end{tabular}

Augenfällig ist die unterschiedliche Überlieferungssituation der einzelnen Motettenteile deren Text zur Liturgie des Stundengebetes am Gründonnerstag gehört. Nur die Chorbücher in München und Stuttgart weisen die Reihenfolge Qui prophetice prompsisti - Qui expansis in cruce - Vita in ligno auf, ein Umstand, der mit den Stuttgarter Kopiertätigkeiten Ludwig Dasers an dessen neuem Dienstort 
zusammenhängen dürfte. ${ }^{83}$ Etwa weitere zehn Quellen tradieren ausschließlich die tertia pars, die übrigen Handschriften und Drucken weichen in ihrer Reihenfolge von jener im Münchner Chorbuch D-Mbs Mus.ms. Io gänzlich ab und stellen das Vita in ligno an den Anfang. Wie Walter Gerstenberg vermerkt, ist die Reihenfolge der einzelnen Teile bereits in der einstimmigen Überlieferung äuBerst uneinheitlich ${ }^{84}$ und tatsächlich mag dies ein Grund für die meist anzutreffende Umstellung sein, obgleich der Text in der oben beschriebenen Reihenfolge in süddeutschen Diözesen durchaus gebräuchlich war. ${ }^{85}$ Logischer scheint aber, den Grund für die umgestellte Überlieferungsreihenfolge in der Entstehungsreihenfolge der einzelnen Motettenteile zu suchen, die von Wagenrieder in dessen Brief vom 23. Mai I 537 folgendermaßen beschrieben wird:

[...] Schikh demnach yetz E f g hiermit 7 stukh. zwo mutet[en] od[er] ewangelia so Josquin selig[er] gemacht. wie wol sy nit New aber seer guet vnd künstlich sein, vnd nit, im register stend, aber das vita in ligno steet im register, doch nur der selb tayl allain. Der ist der letst, ludwig Sennfl hat sider die zween ersten tayl darzue gemacht, die ich dann auch nach ordnung wie sy stend nacheinand $[\mathrm{er}]$ geschriben hab, $[\ldots]^{86}$

Für die schwer festzulegende Chronologie der Senfl'schen Werke lässt sich nun aus der Überlieferungssituation ein wichtiger Hinweis auf den terminus ante quem für die drei Motettenabschnitte gewinnen: Da das Vita in ligno bereits in dem von Herzog Albrecht an Lukas Wagenrieder übersandten Inventar vom 23. Juli I 536 enthalten ist, muss es vor diesem Datum komponiert und an Albrecht geschickt worden sein. Einen noch genaueren Anhaltspunkt für die Entstehungszeit dieser prima pars bietet die früheste Intabulierung in der Handschrift D-B Mus. ms. 40 632, die ca. I 528 (wohl am Hof Wilhelms IV. in München) niedergeschrieben wurde. ${ }^{87} \mathrm{Da}$ bislang keine genuinen Lautenkompositionen von Senfl bekannt sind, dürfte die vokale Fassung von Vita in ligno somit bereits vor I 528

83 Franz Körndle, Art. „Daser, Ludwig“, in $M G G^{2}$, Personenteil Bd. 5, Kassel u.a. 200 I, Sp. $458-46 \mathrm{I}$.

84 Senfl, SW, Bd. XI: Liturgische und allgemein-geistliche Motetten I, hrsg. von Walter Gerstenberg, Wolfenbüttel/Zürich I974, S. I25.

85 Antiffanarium per circulum anni [Antiphonarium Augustense], Augsburg: Erhard Ratdolt, I 495 (GW 2062, verwendetes Exemplar: D-Mbs 2 Inc.c.a.3 I 59), fol. $24^{\mathrm{r}-\mathrm{v}}$ oder auch Antiphonarium Pataviense, Wien: Johannes Winterburger, I5I9 (VDi6 A 2946), Faksimile hrsg. von Karlheinz Schlager, Kassel u.a. 1985 (EdM 88), fol. $45^{\text {r }}$.

86 Edition auch in Bente, Neue Wege (wie Anm. 4), S. 338.

87 Christian Meyer, Sources Manuscrites en tablature, luthe et théorbe (c.1500-c.1800), Bd. II: Bundesrepublik Deutschland, Baden-Baden u.a. 1994 (Collection d'Études Musicologiques 87), S. $65-$ 67. 
vorgelegen haben und kursiert sein. Es besteht also die Möglichkeit, dass sich dieser Motettenteil auch unter jenen 4- bis 6stimmigen Kompositionen befunden hat, die in den I526 von Wagenrieder niedergeschriebenen und von Senfl nach Königsberg geschickten sechs schwarz eingebundenen Stimmbüchern aufgezeichnet waren. Die Entstehungszeit der beiden anderen Motettenteile kann dagegen nur grob auf die Zeit der ersten Hälfte der I $530 e r$ Jahre und vor I 537 eingegrenzt werden, da Wagenrieders Formulierung „sider“ keine genaueren zeitlichen Eingrenzungen zulässt.

Während aber diese Motetten, zusammen mit vielen anderen Kompositionen aus der Münchner Hofkapelle den Brandenburg-Preußischen Hof in der Regel nur auf Anfrage erreichten, wurden drei Werke aus persönlichem Wunsch von Senfl an den Königsberger Hof übersandt. Es handelt sich um die Kompositionen Quid retribuam domino (6v.), De profundis clamavi - A custodia matutina (5v.), und Deus in adiutorium - Exultent et laetentur (4v.). Am 20. Juli I 535 schreibt Senfl:

Durchleuchtiger Hochgeborener Fürst, Genädiger herr, E F G. sein mein underthenig gehorsam willig diennst allzeit zuuor berait, Genädiger herr. von $\mathrm{E} f \mathrm{~g}$. Ist mir ein schreiben. sampt dreien Tenorn vnd Texten vor lannger Zeyt vber=antwort worden, Darinn ich E $\mathrm{f} g$. gnedigen willen ainer fürstlichen vereerung. underthenigklich vernomen, Aber Nachmalen, gemelte fürstliche vereerung vnd schannkung. Durch den hochgelerten herren Doctor Joann Apel. aus E f g. hayssen. mit höchsten freiden. verno=men, Nemblichen dergestallt, das gedachter doctor apel. mir von wegen vnd In Namen E f g. durch herren hieronimus bombgartner, burgern vnd des Raths Zue Nueremberg hat lassen antwurten. geen München, Ein schone Zwifache vergulte schewren. aufs pesst gemacht auf funfftzig gulden Rh. vnd auf paiden poden. E. f. g. vnd derselben gemahel meinr gne=digsten Frawen klainat vnd wappen, dabey auch fünfftzig gulden Rh. an gellt, vnd gueter Müntz. Der fürstlichen hohen gaben vnd grosser vererung sag Ich sambt meiner lieben hausfrawen, höchsten. vnd vnnderthenigisten dannkh. Erkenn mich auch pillich. das Ich solch fürstliche gab, weder mit voran $\mathrm{E} f \mathrm{~g}$. gesannter, Noch ytziger hiemit gesanter Music, lanng nit verdienen kan, Wiewol Ich $\mathrm{E} f \mathrm{~g}$. des hochtrefflichen verstands wol Erkenn. E $f$ g. werden meinen klainen vnderthenigen. vleys. vnd willen. darfür gnedigklich annemen, vnd Die Musicam so ich yetz $\mathrm{E} f \mathrm{~g}$ vbersennde, In gne=digem willen empfahen, Es seind $\mathrm{E} f \mathrm{~g}$. drey gesannt Tenores, mit vier stimben gesetzt, dabey vbersennde Ich auch Ein klaine dannkh sagung. vmb E f g. furstliche vereerung. mit Sex stimen gesetz. vnd Intituliert also, Quid retribua[m] D[omi]no pro om[n]ibus que retribuit mihi: Calicem salutaris accipia[m]; \& nome[n] D[omi]ni inuocabo. Darzue schikh Ich E f g. Zwen psallm ainen mit vieren, Deus in adiutorium 
meum Intende; Den anndern mit fünffen. De profundis cla=maui ad te $D\left[\right.$ omi]ne; $[\ldots]^{88}$

Erst drei Jahre nach Senfls Nachfrage von I 532, sieben Jahre nach Michael Spilbergers Brief von I 528 und neun Jahre nach der Übersendung des mutmaßlichen Hochzeitsgeschenkes von sechs Stimmbüchern (I526) erhielt Senfl also eine Entlohnung vom preußischen Herzog. Zwar hatte Albrecht das Geschenk an Senfl keineswegs vergessen, allerdings scheint sogar ihm die lange Wartezeit von nahezu Io Jahren etwas unangenehm gewesen sein, weshalb er den Gedanken an die „22 preussisch ellen damast“ fallen ließ und ein Geschenk von ungleich höherem Wert nach München übersandte: einen zweifach vergoldeten Pokal, ${ }^{89}$ verziert mit seinem und dem Wappen seiner Frau, zusammen mit 50 rheinischen Gulden. Der Dankbrief Senfls wie auch die Umstände des Geschenkes werden durch einen bislang unbekannten Brief von Dr. Johann Apel, Kanzler Herzog Albrechts, vom 8 . April I 535 zusätzlich erhellt: ${ }^{\circ}$

... Vnd meines Herrn einen ges... vmb dem Ludwig Senfel Schweitzer genannt, welcher mir anzeigt das ehr das gelt nit lang werde behal[ten], vnd für gut angesehen im die fünftzig gülden zuschicken, vnd vmb die vberig[en], fünfzigk ein verguln scheurn mach[en] zulassen. damit ehr also bald nit drumb kum. Also bin ich willens beÿ meinem Schwager Arnoldt Wenken ein schön tringkgeschir machen zulassen mit eur $\mathrm{f}$. g. vnd derselben geliebt[en] gemahel meiner genedigst[en] frauen Wapen. Versich[er] auch es werd eurn f. g. auch nit misfallen, So ehr will ehr, welcher mir den rhadt gegeben, bedes scheurn vnd gelt dem gedacht[en] Schweitzer neben meinem schreiben, an alle schon zuschicken. nach dem ihr den man auch lieb hat vnd guts als ein musicus günnet. ...

Der Brief ist in mehrfacher Hinsicht aufschlussreich: Im Frühjahr des Jahres I 535 hatte der Herzog dem Komponisten offensichtlich Ioo Gulden als Dank

88 Berlin, Geheimes Staatsarchiv Preußischer Kulturbesitz, XX, HBA, A4, Kasten 193, 20. Juli I 535. Edition auch in Bente, Neue Wege (wie Anm. 4), S. 329 f. Die im Brief durch lateinische Schrift hervorgehobenen Motettentitel werden hier durch Kursivierungen kenntlich gemacht.

89 Vgl. Deutsches Wörterbuch von Jacob Grimm und Wilhelm Grimm online, (http://www. woerterbuchnetz.de/DWB?lemma=scheuer bzw. http://www.woerterbuchnetz.de/DWB? lemma=scheure), Zugriff am 23. Oktober 20I I.

90 Berlin, Geheimes Staatsarchiv Preußischer Kulturbesitz, XX, HBA, A4, Kasten I93, A.Z.3.34.26 (8.4.I535). Soweit bekannt, wurde der Brief in der Musikforschung bislang nicht berücksichtigt. Lediglich ein Hinweis darauf findet sich in D. Theodor Muther, Doctor Johann Apell. Ein Beitrag zur Geschichte der deutschen Jurisprudenz im sechszehnten Jahrhundert, Königsberg I86I, S. 5 I. 
für die Stimmbücher I 526 angeboten und wollte ihn mit diesem hohen Betrag für die lange Wartezeit entschädigen. Wie aus dem Brief Apels vom 8. April I 535 hervorgeht, nimmt Senfl in realistischer Selbsteinschätzung jedoch an, dass er das Geld nicht lange behalten würde und bittet, ihm fünfzig Gulden zu schicken und für die anderen fünfzig einen vergoldeten Pokal machen zu lassen. Apel in Nürnberg zeichnete demnach für die Anfertigung des Pokals verantwortlich und gab ihn bei seinem Schwager, Arnold Wenk, nach dem 8. April I 535 in Auftrag. ${ }^{91}$ Sechseinhalb Wochen später, am 22. Mai, berichtet er seinem Herzog, dass sich der Pokal noch immer in Nürnberg befände, nun aber an Senfl zugestellt würde. Wenn Senfl seine Danksagung an Albrecht in einem Brief vom 20. Juli 1535 beteuert, bedeutet das nichts weniger, als dass die in Senfls Brief enthaltene Musik (entweder vollständig oder teilweise) in der Zeit zwischen der Überstellung des Pokals, also nach dem 22. Mai, und vor Niederschrift des Briefes komponiert worden sein muss. Rechnet man die Zeit der Überstellung des Geschenkes bzw. der Zustellung der Briefe hinzu, bleibt ein ungefähres Zeitfenster von etwa sechs bis sieben Wochen (Ende Mai bis Mitte Juli), in denen wenigstens Quid retribuam domino komponiert wurde. ${ }^{92}$ Die Anfertigung eines Bechers oder Pokals aber sollte für den Herzog eine durchaus gebräuchliche Art der Dankesbezeigung werden. I 540 erhalten auch Lukas Wagenrieder, Joachim Camerarius und Philipp Melanchthon ein derartiges Geschenk verehrt, ${ }^{93}$ I 543 auch Georg Wyltzel. ${ }^{94}$ Doch keiner dieser Becher war so aufwändig gearbeitet wie Senfls: Sie wurden nur aus Silber gefertigt.

Senfl indes wählte einen sicheren Weg, damit der Herzog dieses, sein Geschenk, auch als besondere Musiklieferung von den bisher übersandten Werken unterscheiden konnte: Er benannte die Motetten ausdrücklich in seinem Brief. Besonders die „klaine dannkh sagung. vmb E $\mathrm{g}$. furstliche vereerung. mit Sex stimen gesetz. vnd Intituliert also, Quid retribua[m] D[omi]no pro om [n]ibus que retribuit mihi: Calicem salutaris accipia $[\mathrm{m}]$; \& nome [n] D[omi]ni inuocabo.", erscheint in dem Schreiben hervorgehoben und obwohl Quid retribuam domino verloren ist, können einige Überlegungen zur Konzeption dieser Motette angestellt werden.

9I Albrecht und Wenk waren spätestens seit I527 miteinander bekannt und standen immer wieder für die Anfertigung von Schmuckstücken in Kontakt. Siehe etwa die mehrfachen Einträge in Berlin, Geheimes Staatsarchiv Preußischer Kulturbesitz, XX HA Ostpreußische Folianten 36 , fol. $6 \mathrm{I}^{\mathrm{v}}-62^{\mathrm{r}}$, fol. I I I ${ }^{\mathrm{r}}$, fol. II $8^{\mathrm{r}}-\mathrm{I} I 9^{\mathrm{r}}$ aus den Jahren $\mathrm{I} 527 / 28$ oder Ostpreußische Folianten Nr. 37, S. I03 (83)-I04 (84), S. I 58 (I 40) bzw. S. I66 (I60) von I 532.

92 Bente, Neue Wege (wie Anm. 4), S. 69 nimmt an, dass De profundis vor I 535 entstanden ist. Diese Annahme ist jedoch nicht zwingend.

93 Tschackert, Urkundenbuch (wie Anm. I9), Nr. I23 I, S. 395, möglicherweise auch Nr. I226, S. 394.

94 Eitner, „Zwei Briefe von Georg Wytzel“ (wie Anm. 5). 
Mit ihrer außergewöhnlichen großen Besetzung für sechs Stimmen ist sie eine von I2 Motetten in einem Gesamtschaffen von ca. I4O Motetten..$^{95} \mathrm{Da}$ einige dieser Werke mit besonderen Kompositionstechniken wie Ostinato (Philippe qui videt me) oder Kanon (z.B. in Veni sancte spiritus, Media vita in morte sumus oder Sic deus dilexit) gearbeitet sind, darf angenommen werden, dass die Motette ebenfalls Besonderheiten aufwies, erst recht, da sie ja als Dedikationsmotette komponiert war.

Beim Text der Motette Quid retribuam domino pro omnibus quae retribuit mihi. Calicem salutaris accipiam et nomen domini invocabo. („Wie soll ich dem Herrn all seine Wohltat vergelten, die er an mir tut? Ich will den Kelch des Heils annehmen und den Namen des Herrn anrufen.") handelt es sich um die Verse I2-I3 aus Ps. II6. Mit der Wahl der mehrstimmigen Ausarbeitung gerade dieses Psalmabschnittes stellt sich Senfl bewusst in die Tradition seines Lehrers Heinrich Isaac, der bekanntlich eine dreistimmige Motette Quid retribuam tibi Papst Leo X. widmete, da letzterer dem Komponisten I5IS eine Pension gewährt hatte..$^{96}$

95 Die übrigen erhaltenen und sicher Senfl zuzuschreibenden Motetten für sechs Stimmen sind: Alleluia, mane nobiscum; Anima mea liquefacta est-2.p. Invenerunt me custodes - 3.p. Filiae Hierusalem; Ave Maria gratia ... virgo serena - 2.p. Ave vera humilitas; Philippe qui videt me; Quem terra pontus; Sancte Pater divumque decus/Sancte Gregori confessor - 2.p. Tu si quidem primum / Adesto nostris precibus; Verbum caro factum est (i) - 2.p. Plenum gratia et veritate - 3.p. In principio erat verbum; Veni sancte spiritus (i); Media vita in morte sumus (ii) - 2.p. Sancte Deus sancte fortis; Alma redemptoris mater - 2.p. Tu quae genuisti - 3.p. Virgo prius; Sic deus dilexit mundum. Für die - wenn auch sehr vorsichtige - Zuschreibung der ausschließlich anonym überlieferten Motette En quam honesta an Senfl von Henrik Glahn, ",Samdrægtighedens velsignelse” - musikalsk belyst gennem nogle motetter fra det I6. århundrede", in Musik \& forskning I 5 (I989/90), S. 7-34 fehlen eindeutige Beweise. Die Echtheit der Motette Hodie in Jordane baptizato - 2.p. Descendit spiritus sanctus ist fraglich. Sie stammt möglicherweise von Maistre Jhan; auch bei dem möglicherweise von Heinrich Isaac komponierten Spiritus Sanctus in te descendet ist die Autorschaft noch nicht geklärt. Emma Clare Kempson, The Motets of Henricus Isaac. Transmission, Structure, and Function, PhD Diss. University of London I998, Bd. I, S. 32 I-325 schreibt sie aufgrund der Vertrauenswürdigkeit der frühen Quelle (Autorzuschreibung in D-Rp C I 20) gegenüber der späten Überlieferung (Autorzuschreibung in D-Mbs Mus.ms. I 536/3 und RISM I $564^{3}$ ) Senfl zu.

96 Erschienen in RISM I $542^{8}$. Neuausgabe in Georg Rhau, Musikdrucke aus den Jahren $153^{8-1545,}$ Bd. IX: Tricinia ..., hrsg. von Thomas Noblitt, Kassel u.a. 1989, S. 76-78. Zur Echtheitsfrage siehe Martin Just, Studien zu Heinrich Isaacs Motetten, 2 Bde., Diss. Universität Tübingen I96o, vor allem Bd. I, S. 7If., I8of. und Bd. 2, S. 6If., der Martin Staehelin, Die Messen Heinrich Isaacs, Bern/Stuttgart 1977 (Publikationen der Schweizerischen Musikforschenden Gesellschaft 28), Bd. 2, S. 79f. widerspricht. Siehe auch Martin Staehelin, „Eine musikalische Danksagung von Heinrich Isaac - Zur Diskussion einer Echtheitsfrage“, in Quellenstudium und Musikalische Analyse - Festschrift Martin Just zum 70. Geburtstag, hrsg. von Peter Niedermüller, Cristina Urchueguía und Oliver Wiener, Würzburg 200 I, S. 23-32. 
Tabelle 3: Vergleich der Motettentexte von Quid retribuam in den Vertonungen von Heinrich Isaac und Ludwig Senfl

\begin{tabular}{|c|c|}
\hline VERTONTER TEXT ISAACS & BiBELSTELLE \\
\hline $\begin{array}{l}\text { Quid retribuam tibi, Leo, o summe } \\
\text { Pontifex, pro his quae in me contulisti? }\end{array}$ & $\begin{array}{l}\text { nach Ps. I I6, I2: } \\
\text { Quid retribuam Domino } \\
\text { pro omnibus quae retribuit mihi? }\end{array}$ \\
\hline Cantabo canticum novum. & $\begin{array}{l}\text { nach Ps. I } 43,9: \\
\text { Deus canticum novum cantabo tibi. }\end{array}$ \\
\hline Semper laus tua in ore meo. & $\begin{array}{l}\text { nach Ps. } 33,2 \text { : } \\
\text { Benedicam Dominum in omni tempore. } \\
\text { Semper laus eius in ore meo. }\end{array}$ \\
\hline $\begin{array}{l}\text { Argentum et aurum non est mihi: } \\
\text { quod autem habeo, hoc tibo do. }\end{array}$ & $\begin{array}{l}\text { nach Acta 3,6: } \\
\text { Argentum et aurum non est mihi: } \\
\text { quod autem habeo, hoc tibi do. }\end{array}$ \\
\hline $\begin{array}{l}\text { Et si oportuerit me mori tecum, } \\
\text { non te negabo. }\end{array}$ & $\begin{array}{l}\text { nach Mt. } 26,35 \text { : } \\
\text { Ait Petrus: etiam si oportuerit me mori tecum, } \\
\text { non te negabo }\end{array}$ \\
\hline VERTONTER TEXT SENFLS & BIBELSTELLE \\
\hline $\begin{array}{l}\text { Quid retribuam domino pro } \\
\text { omnibus quae retribuit mihi. }\end{array}$ & $\begin{array}{l}\text { Ps. I I6, I } 2 \text { : } \\
\text { Quid retribuam Domino pro } \\
\text { omnibus quae retribuit mihi. }\end{array}$ \\
\hline $\begin{array}{l}\text { Calicem salutaris accipiam } \\
\text { et nomen domini invocabo. }\end{array}$ & $\begin{array}{l}\text { Ps. I I6, I3: } \\
\text { Calicem salutaris accipiam } \\
\text { et nomen Domini invocabo. }\end{array}$ \\
\hline
\end{tabular}

Während Isaacs Komposition eine Kompilation aus verschiedenen Psalmen und Textstellen des Alten Testaments darstellt, verwendet Senfl den exakten Wortlaut von Ps. I I6 (Tabelle 3). Es bedarf keiner Textänderung, da der Psalmtext perfekt für die Situation passt: Im Unterschied zu den beiden anderen Motetten legt Senfl Wert darauf, die gesamte Passage niederzuschreiben und so darauf hinzuweisen, dass er die beigefügte Motette nicht nur auflisten wollte. Der Komponist war vielmehr daran interessiert, dem Herzog sehr explizit in mehrfacher Weise seine Dankbarkeit zu zeigen: Er zitiert beide Psalmverse sowohl auf Deutsch als auch auf Lateinisch und fügt schließlich noch eine Vertonung des lateinischen Textes für sechs Stimmen bei. Der erste Satz des gewählten Psalmausschnitts thematisiert die Frage der gewährten Gunst und der Unwürdigkeit des Geschenks. Senfl verwendet genau diese Worte in seinem Brief wenn er schreibt „Erkenn mich auch pillich, das ich solch furstliche gab, weder mit voran E f g. gesannter, noch ytziger hiemit gesanter Music, lanng nit verdienen kann ...". Der zweite Satz des vertonten Abschnittes thematisiert den Erhalt des 
Kelchs des Heils („,calicem salutaris accipiam“) und deutet ganz offensichtlich auf den geschenkten Pokal. Neben Dankbarkeit dürfte für Senfls deutsche Umschreibung des lateinischen Textes auch ein ganz praktischer Grund eine Rolle gespielt haben: Mit einer solchen Übersetzung ermöglicht Senfl es dem Herzog auf elegante Weise, den Inhalt des auskomponierten Psalmtextes zu verstehen und zu würdigen.

Wie angesprochen fiel Senfls Wahl aus mehreren Gründen auf Ps. I I6, einen Dankes- und Trostpsalm für die Errettung aus Unheil, Bedrängnis und Not, ${ }^{97}$ der gleichzeitig auch ein tiefes Gottvertrauen ausdrückt. ${ }^{98}$ Die von Senfl vertonten Verse I2-I 3 bilden hierbei das Kernstück: Der angesprochene Kelch des Heils ist ein Kelch der Heilung, der Erlösung und des Trostes; er wird zum Lobpreis Gottes für aus Gnade erwiesene Wohltaten, in Senfls Fall also für die Gewährung eines Gnadengeschenkes. Zwar zählt der Psalm nicht zu Martin Luthers favorisierten Themen, doch zeigen die verschiedentlichen Äußerungen und Interpretationen des Reformators die Vielschichtigkeit des Psalmtextes und offenbaren den - nach Luthers Sicht - dem Psalm innewohnenden Erlösungsgedanken. ${ }^{99}$ Luther sieht in der Annahme des Heilskelches die Aufforderung an jeden gläubigen Christen zur Verkündigung des Heils Gottes. ${ }^{100}$ Der Kelch wird für ihn zu einem Symbol für den Sieg Gottes über den Tod und die damit erfolgte Heilung von der Erbsünde. Er sieht darin die Pflicht, allen Menschen von den guten Werken Gottes zu erzählen und Gottes Lobpreis zu predigen. Gleichzeitig ist es zentrales Anliegen Luthers, diesen Kelch als einen Kelch der Gnade aufzufassen. Erst mit der Erfüllung der oben genannten Pflichten, der Danksagung an Gott, der Predigt über seine Wohltaten und dem Lobpreis seines Namens, erhält der Gottesdienst einen Sinn und das erste Gebot, die Ehrung Gottes, wird erfüllt. ${ }^{\text {IOI }}$ Das Abendmahl wiederum, für das der Kelch sinnbildlich steht, ist nach lutherischer Auffassung ein Gnadengeschenk Gottes. In ihm wird Christi Kreuzestod und der Erlösung der sündigen Menschheit gedacht. ${ }^{102} \mathrm{Ob}$ sich Herzog Albrecht der Komplexität des von Senfl interpretierten Textes bewusst

97 Hans-Joachim Kraus, Psalmen, 2. Teilbd.: Psalmen 60-I 50, Neukirchen-Vluyn ${ }^{6}$ I989 (Biblischer Kommentar Altes Testament XV/2), S. 968-973.

98 Ps. I I6: ${ }^{6}$ Der Herr behütet die Einfältigen. Wenn ich unterliege / so hilft er mir. ${ }^{7}$ Sei nu wieder zufrieden / meine Seele / denn der Herr tut dir Guts. Übersetzung zitiert nach Neues Testament und Psalter in der Sprache Martin Luthers für Leser von heute, Ausgabe nach dem Wortlaut der Lutherbibel von 1545, Hamburg 1982, S. 675.

99 D Martin Luthers Psalmen=Auslegung, 3. Bd.: Psalmen 91-150, hrsg. von Erwin Mühlhaupt, Göttingen I965, S. 317-327.

I00 D. Martin Luthers Werke, Kritische Gesamtausgabe, Bd. 37, Weimar I9I0, S. 424.

IOI D. Martin Luthers Werke, Kritische Gesamtausgabe, Bd. 38, Weimar I9I2, S. 56.

IO2 Siehe Dorothea Wendebourg, „Taufe und Abendmahl“, in Luther Handbuch, hrsg. von Albrecht Beutel, Tübingen ${ }^{2} 2010$, S. 4I4-423. 
war und ob die Vermittlung einer derartigen Interpretation überhaupt Senfls Intention war, muss freilich dahingestellt bleiben. $\mathrm{Zu}$ konstatieren bleibt die enge Verbindung beider Männer zu Martin Luther und der gegenseitige Respekt für die kunstvollen Kompositionen des einen, wie das Wissen um das Interesse für derlei Werke des anderen. Von den drei übersandten Motetten war diese sicherlich die bedeutendste für Senfl. Hier geschah nichts aus Zufall.

Der exzeptionelle Rang, den Quid retribuam domino für Senfl hatte, wird noch durch ein weiteres kompositorisches Detail unterstrichen: Im Unterschied zur Fokussierung auf den bewusst ausgewählten Psalmausschnitt dieser Dankesmotette stellen die Werke De profundis, 5v. und Deus in adiutorium, 4v. Komplettvertonungen der Psalmen I 30 bzw. 70 dar. Obwohl beide Texte in der Liturgie verwendet werden konnten, scheint ein liturgischer Gebrauch nicht intendiert gewesen zu sein, jedenfalls geben die Kirchenordnungen des Herzogs über eine solche Verwendung keinerlei Auskunft. ${ }^{103}$ Die Überlieferungssituation zeigt die ganz eigene Rezeption, die die beiden Motetten außerhalb des Briefverkehrs zwischen Königsberg und München erfuhren: De profundis zählt - ähnlich Quid prophetice prompsisti - zu Senfls bekanntesten Motetten (Tabelle 4) und ist vornehmlich in Quellen mit protestantischem Hintergrund überliefert. Die Motette genoss sogar eine derartige Beliebtheit, dass sie als Modell für eine fünfstimmige Parodiemesse von N. Grüntler Trojanus diente, einem Komponisten, der bislang nicht weiter bekannt ist. ${ }^{104}$ Deus in adiutorium (Ps. 70, 2-6) dagegen erfuhr außer einer Aufnahme in den zweiten Band der Psalmorum selectorum, quatuor et plurium vocum (RISM I553') ausschließlich Eingang in zahlreiche musiktheoretische Schriften und blieb bis ins I7. Jahrhundert Beispiel für die Verwendung der lydischen Tonart, eine Rezeption, die mit dem Abdruck in Heinrich Glareans Dodekachordon ihren Anfang nahm (Abbildungen I und 2). ${ }^{\text {Ios }}$

I03 Die evangelischen Kirchenordnungen des XVI. Jahrhunderts, hrsg. von Emil Sehling, Bd. 4: Das Herzogtum Preußen, Polen, die ehemals polnischen Landesteile des Königreichs Preußen, das Herzogtum Pommern, Neudruck der Ausgabe Leipzig I9 I I, Tübingen I970.

IO4 Edition in Meßzyklen der frühprotestantischen Kirche in Leipzig, hrsg. von Laura Youens, Tutzing I984 (Münchner Editionen zur Musikgeschichte 5), S. I33-I75.

I05 Henricus Loriti Glareanus, Dodekachordon, Basel: Heinrich Petri I 547, S. 332-333. Weiters: Gallus Dressler, Practica modorum (Jena: Richzenhain I 56I); Eucharius Hoffmann, Doctrina de tonis seu modis musicis (Greifswald: Ferber I 582); Peter Eichmann, Praecepta musicae practicae (Stettin: Müller I604); Otto Siegfried Harnisch, Artis Musicae Delineatio (Frankfurt: Richter I608); Joachim Thuringus, Nucleus musicus de modis seu tonis (Berlin I622). Erwähnt wird die Motette darüber hinaus in Johannes Nucius, Musices poeticae, sive de compositione cantus praeceptiones (Neiße: Scharffenberg I6I3) und Joachim Thuringus, Opusculum bipartitum (Berlin: Kalle/Runge I624, ${ }^{2}$ I625), der auch Senfls Motetten Tota pulchra es, Vita in lingo, Ave rosa sine spinis, Ave Maria und Grates nunc omnes, eine zu dieser Zeit bereits als Motette etablierte Sequenz, erwähnt. Markus Grassl, „Senfl among the theorists“, Vortrag gehalten im Rahmen 
Ludwig Senfl, Herzog Albrecht und der Kelch des Heils

Tabelle 4: Überlieferung der Motette De profundis clamavi (ii) - 2.p. A custodia matutina (5v.) von Ludwig Senfl ${ }^{\text {IO6 }}$

\section{HANDSCHRIFTEN}

A-Wn Mus.Hs. I 5500

$\mathrm{CH}-\mathrm{Bu}$ F X 5-9

D-D1 Mus. I/D/3

D-Dl Mus. I/D/6

D-EIa s.s.

D-ERu Ms. 473/4

D-GOl Chart. A 98

D-Kl $4^{\circ}$ Ms. Mus. 24

D-LEu 49/5o (nur Altus notiert)

D-Mbs Mus.ms. IO

D-Mu $8^{\circ}$ Cod. ms. 326

D-Mu $8^{\circ}$ Cod. ms. 327

D-Ngm 83795

D-Rp A.R. 89I-892

D-Rtt $2 / 3$

D-SSa HSo229

DK-Kk Gl. Kgl. I 873

PL-Kj Mus. ms. 40 O 3

\section{DRUCK}

RISM I $537^{\mathrm{I}}$

\section{TABULATUREN F. TASTENINSTRUMENTE}

A-Kla Ms. GV $4 / 3$

Brown I $583_{6}$

der Medieval \& Renaissance Music Conference, Barcelona 5.-8. Juli 2011. Vgl. auch Siegfried Gissel, „Glareans Tonarten Lydius und Hypolydius und ihre Berücksichtigung durch die Theoretiker/Komponisten bis etwa I650“, in MD 5I (I997), S. 73-I02. Ich danke Andrea Horz für diesen Hinweis.

Io6 Siehe hierzu auch den umfassenden Kritischen Bericht von Royston Gustavson, Hans Ott, Hieronymus Formschneider, and the ,Novum et insigne opus musicum' (Nuremberg, 1537-1538), Diss. University of Melbourne I998, Bd. 2, S. 87I-892. 


\section{3: Dodecachordi Lydifquartumexemplum \\ $\mathrm{D}$ \\ Eusin adiutoriữ meũ intẽde, in ten de.Do

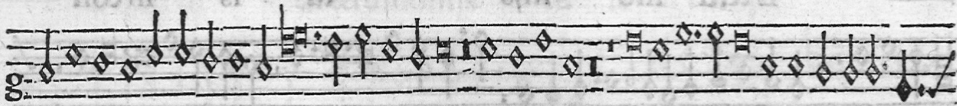 minead adiuuãdũ mefe fti na.Cõfundãti, \& reuereant̆ qquęrũtani

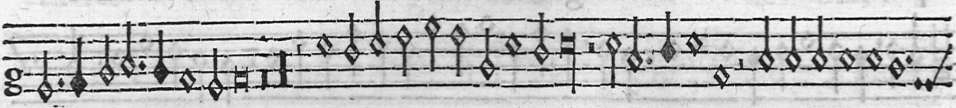 mam me am. auertantur retrorfum $\&$ erubefcãt quolũt mihi mala Auertanturfta
tim eru be feen tes quidis} g cūtmihiEugeĩ. ï. Euge.

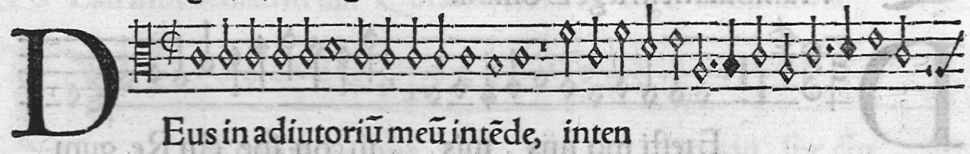

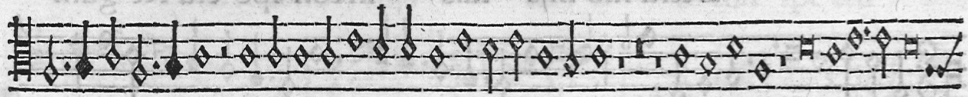
de. Dñead adiuuandũ mefeftina, Côfundantit,\& reuerean

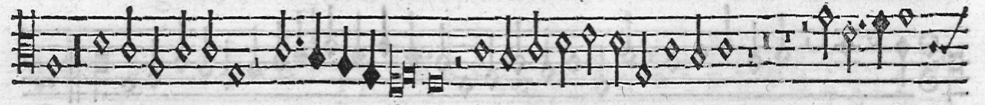
tur,qquerūtaĩamme am.Auertant retrorfum, \& eru befcãt

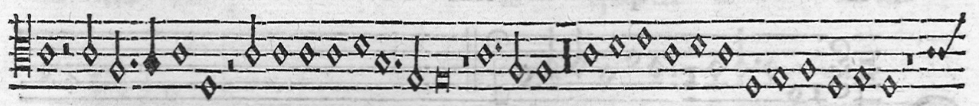

\&erubefcãt quolũt mihi mala.mala, auertãtur ftatim auert. ftatim

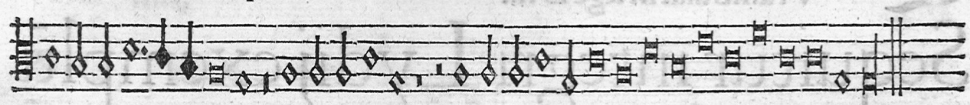
eru be fcen tes qdicũtmihiq dicũtmihiEuge ij. ij.Euge Euge. 


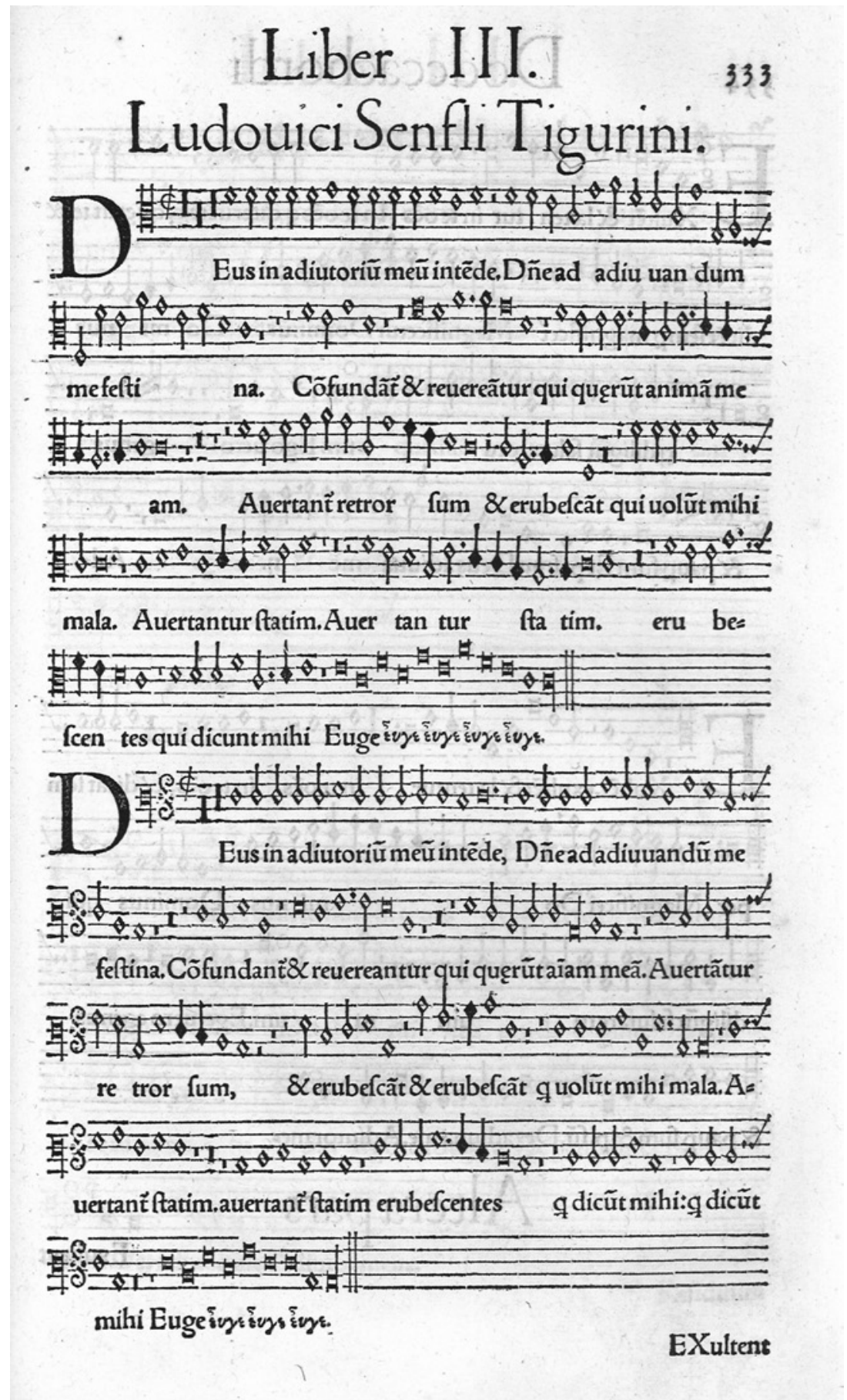

Abb. 2: Henricus Loriti Glareanus, Dodekachordon, Basel: Heinrich Petri I 547, S. 333 
Das kompositorische Bild, das Senfl in diesen beiden Motetten zeichnet, ist dabei durchaus unterschiedlich und es scheint, als ob er dem Herzog verschiedenartige Facetten seiner mehrstimmigen Werke zukommen lassen wollte. Zwar sind beide Kompositionen mit I62 Mensuren (Deus in adiutorium) bzw. I73 Mensuren (De profundis) etwa gleich lang und beide Werke weisen eine großformale Gliederung in zwei Partes mit einer klaren, in mehrere Sinnabschnitte gegliederten textlichen Binnenstruktur auf; in beiden Motetten greift Senfl zudem Konstruktionsprinzipien auf, die bereits in seinen Kompositionen vor I 520 aufscheinen, ${ }^{107}$ und beide Motetten sind in ihrer frühesten Überlieferungsphase sowohl im Münchner Chorbuch D-Mbs Mus.ms. Io kopiert als auch in Formschneiders/Otts Novum et insigne opus musicum (RISM I $537^{\mathrm{T}}$ ) abgedruckt.

Obwohl also beide Werke auf den ersten Blick einige Gemeinsamkeiten und eine ähnliche Ausgangssituation aufweisen, überwiegen die Unterschiede hinsichtlich Satzfaktur zwischen den beiden Werken deutlich. ${ }^{108}$ Dies mag an der geradezu schematischen und bausteinhaften Anlage der Motette liegen, die meist konsequente Imitationen zwischen den einzelnen Stimmen bei vornehmlich durchgehender Konzeption in Ober- und Unterstimmenpaaren aufweist. In Kombination mit der in diesem Satz vorherrschenden deklamatorischhomophonen oder syllabischen Textbehandlung führt dies zwar zu einer mehr als deutlichen Textverständlichkeit, es kann jedoch den Eindruck einer gewissen Schematik nicht verleugnen. Eine besondere Herangehensweise an die Vertonung des Psalmverses lässt sich dennoch beobachten. Trotz der Losgelöstheit von einem cantus prius factus scheinen soggetti der Motette vom einstimmigen Choral inspiriert zu sein. ${ }^{109}$

Ein genauer Blick zeigt, dass Senfl tatsächlich auf liturgische Modelle zurückgreift und bei Textteilen, die der Tagesliturgie ähneln, die entsprechenden einstimmigen Vorlagen wählt: Gerade zu Beginn der prima pars wird die Nähe zur Intonationsformel des Stundengebetes durch die typisch psalmodierenden Tonrepetitionen offenbar (Bsp. 2a und 2b), ${ }^{\mathrm{IIO}}$ ein Prinzip, das Senfl auch im dritten Teil seines Miserere mei anwendet (Bsp. 3a und b).

I07 Ein Beitrag zu den „frühen“ Motetten Senfls ist in Vorbereitung.

Io8 Die Betrachtung bezieht sich auf die Ausgabe der Motetten in Ludwig Senfl, Sämtliche Werke, Bd. III: Motetten, I. Teil: Gelegenheitsmotetten und Psalmvertonungen, hrsg. von Walter Gerstenberg, Wolfenbüttel/Zürich I962, S. 48-52 (Deus in adiutorium) sowie S. 86-90 (De profundis [ii]).

I09 Zur (Nicht-)Verwendung von Psalmtönen in Psalmmotetten siehe Ludwig Finscher, „Zur Cantus-firmus-Behandlung in der Psalm-Motette der Josquinzeit“, in Hans Albrecht in Memoriam, hrsg. von Wilfried Brennecke und Hans Haase, Kassel u.a. I962, S. 55-62.

I IO Senfl, $S W$ III, S. I I9. 
Tonus ferialis.

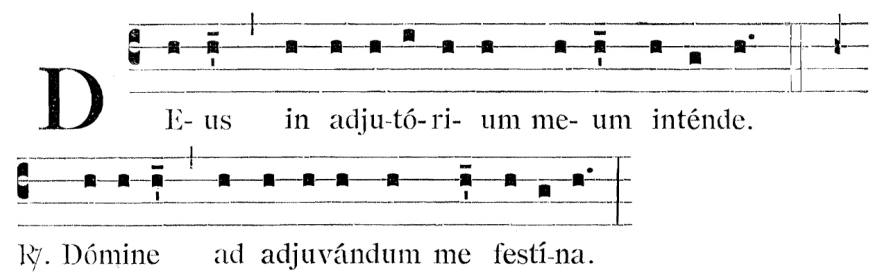

Notenbsp. 2a: Antiphonale sacrosanctae romanae ecclesiae pro diurnis horis, Paris etc., I949, S. $2^{\star}$
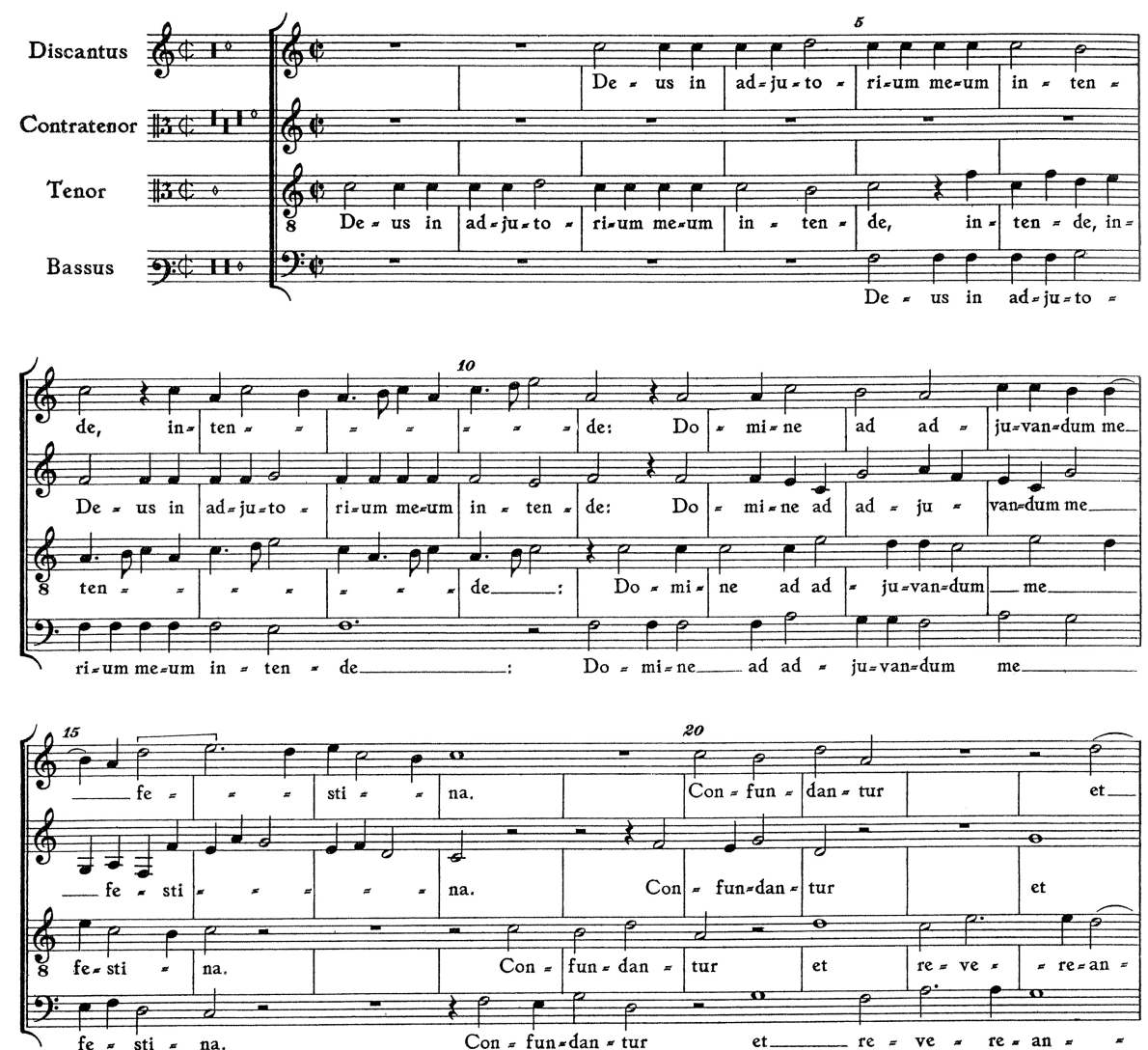

Notenbsp. 2b: Ludwig Senfl, Deus in adiutorium (i) - 2.p. Exultent et laetentur (4v.) Beginn der prima pars, Senfl, $S W$ III, S. 48 
Stefan Gasch

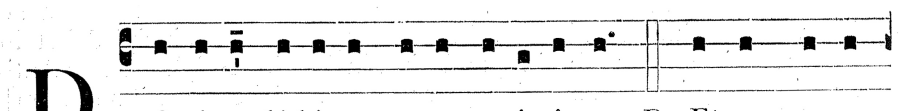

Omi-ne, lá-bi- a me- a apé-ri- es. R⿳亠. Et os me- um

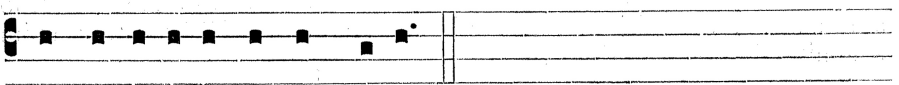

annunti- ábit laudem tu- am.

Notenbsp. 3a: Antiphonale sacrosanctae romanae ecclesiae pro diurnis horis, Paris etc., I949, S. $3^{\star}$
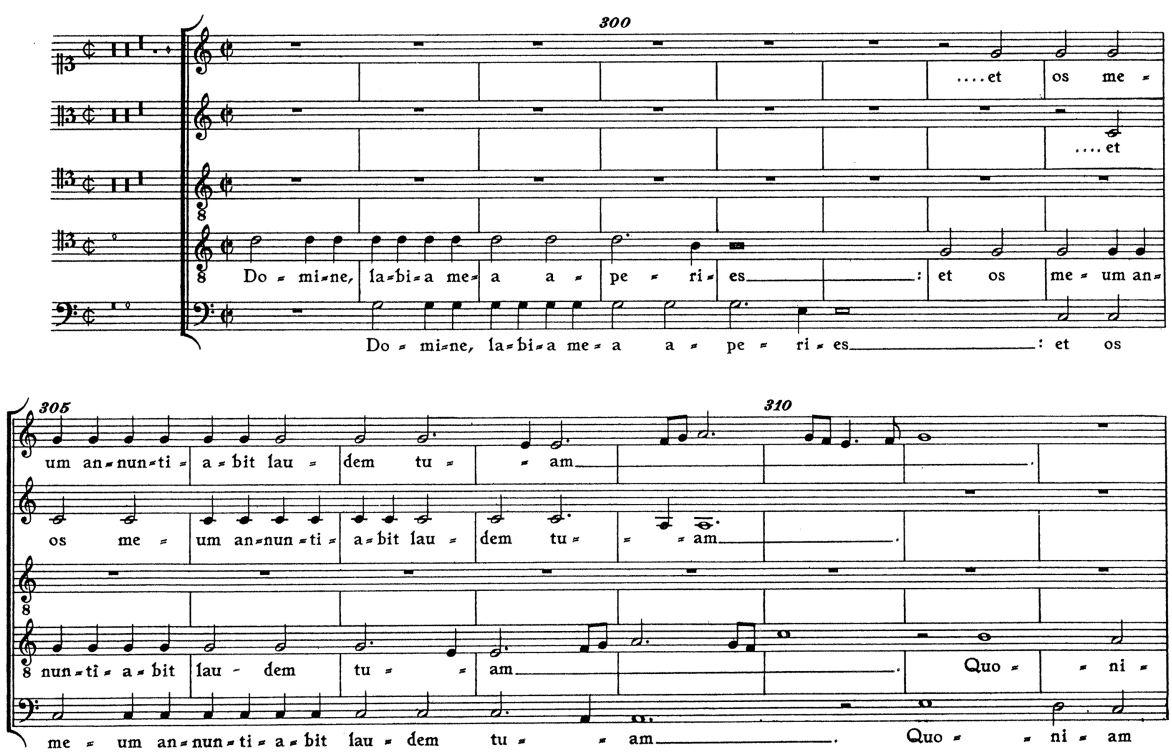

Notenbsp. 3 b: Ludwig Senfl, Miserere mei - 2.p. Asperges me domine / Miserere mei deus 3.p. Domine labia mea aperies / Miserere mei deus (5v.), Beginn der tertia pars,

Senfl, $S W$ III, S. 6 I 
Die Verbindung von ausladender Motette einerseits und liturgienahem Kontext andererseits ist auch in einer weiteren Hinsicht gegeben. Die Vertonung der Intonationsformel „Deus in adiutorium meum intende, Domine, ad adiuvandum me festina“ ist dem eigentlichen Psalmvers „vorgeschaltet“ und durch eine Kadenz vom restlichen Psalm getrennt. Eine ähnliche Herangehensweise ist in Senfls Proprien für die Sonntage nach Pfingsten zu beobachten, ${ }^{11}$ bei denen sowohl Introitus als auch Communiones dadurch charakterisiert sind, dass sie die chorale Intonation nicht mehr einstimmig ausführen, sondern in den mehrstimmigen Satz mit einbinden. In Deus in adiutorium (i) spielt Senfl also mit Konstruktionsprinzipien des motettischen Satzes, präsentiert aber gleichzeitig Eigenheiten, die in seinen Proprienkompositionen aufscheinen. Senfl erleichtert sich damit nicht nur den Einstieg in einen ansonsten gerüst- weil choralfreien Satz, er vereint auf diese Weise auch jahrhundertealte Liturgie mit dem modernen Genre der Psalmmotette.

Ganz anderer Art ist dagegen Senfls Motette De profundis (ii). Das Werk erfährt durch den Abdruck in RISM I537 nicht nur eine ungleich höhere Verbreitung (einschließlich Intabulierungen), in ihr offenbart Senfl auch eine besonders reiche Gestaltungsvielfalt. Obwohl auch hier (wie meist in Psalmmotetten) eine psalmodische Grundlage als durchlaufendes Modell fehlt, bleiben gewisse Anklänge daran erhalten (M. I 8-22, 9off.). Wie in Deus in adiutorium (i) sind auch in De profundis oftmals Stimmpaarbildungen und Imitationen zu finden. De profundis ist jedoch von einer melismatischen Textvertonung geprägt, die besonders wichtige Textabschnitte hervorhebt. Hierunter fallen beispielsweise die gegensätzlichen Imitationsanfänge der beiden Partes, die vom Text inspiriert werden und diesen in gewisser Weise abbilden; oder auch das Insistieren auf Textabschnitten wie ,in vocem deprecationis meae“ („die Stimme meines Flehens“; M. 35-47), „misericordia“ („Barmherzigkeit“; M. I30-I38), „redemptio“ („Erlösung“; M. I 50-I 55) oder „iniquitatibus eius“ (,seinen Sünden“; M. I63-I70). Die fünfstimmige Besetzung der Motette erlaubt es wiederum, die einzelnen Textabschnitte auf unterschiedliche Gruppen aufzuteilen, was zu einer Aufspaltung in einen Ober- und Unterstimmenchor mit der verbindenden Achse des Contratenors, einem scheinbaren „mehrchörigen Design“ dieser Textstellen innerhalb der Gesamtkomposition führt. Indem er verschiedenste Techniken wie Melismatik, Mehrchörigkeit, syllabische und homophone Textdeklamation (vor allem zur Erinnerung an den psalmodischen Charakter des Textes) oder auch Stimmtausch (M. 36-46) bewusst einsetzt, und indem er diese Techniken mit Wiederholung und Komplementärrhythmen kombiniert (M. 90-94), stellt 
Senfl eine außerordentliche Vielzahl von Kompositionstechniken vor. Auf diese Weise gelingt es ihm, den Psalmtext in einer höchst individuellen Art und Weise $\mathrm{zu}$ interpretieren und die Bedeutung einzelner Textstellen plastisch herauszuarbeiten. Sein Bewusstsein für die ihm zur Verfügung stehenden Kompositionstechniken ermöglichen es Senfl somit, sein ganz individuelles Textverständnis und seine persönliche „Lust“ an diesen schönen Worten auszudrücken.

Eine neuerliche Auseinandersetzung mit der Korrespondenz Senfls mit Herzog Albrecht von Brandenburg-Preußen fördert somit verschiedenste Erkenntnisse sowohl im Hinblick auf die Chronologie Senfl'scher Werke als auch auf sein soziales Umfeld zu Tage: Senfl hat für die feierliche Hochzeit von Kasimir von Brandenburg-Ansbach mit Susanna von Bayern möglicherweise nicht nur eine seiner frühesten Psalmmotetten, sondern auch das Akrostichon-Liedpaar Capitan Herr Gott und So Glück und Stund' beigetragen. Und seine, in dieser Zeit geknüpfte Bekanntschaft mit dem Bruder des Bräutigams führte nach der Übersendung vereinzelter Briefe zu Beginn der I530er Jahre zu einem regen Schriftwechsel. Neben den bereits bekannten Details zu einigen Liedern Senfls, gibt dieser vor allem Aufschluss über die Entstehungszeit der Motettenabschnitte Qui prophetice prompsist - Qui expansis in cruce ( $5 \mathrm{v}$.$) , die um die Mitte der I 530 e r$ Jahre und vor I 537 komponiert worden sein müssen. Sie wurden als Ergänzung der bereits vor 1528 entstandenen Motette Vita in ligno komponiert und bilden deren beide erste Partes. Diese Datierung hat Konsequenzen für das Münchner Chorbuch ıо (D-Mbs Mus.ms. Io). Es ist die früheste Quelle für die vorgenannten Motetten und enthält eine Reihe anderer Kompositionen, die nach Königsberg gesandt wurden. Derzeit wird das Bindedatum des Chorbuches sehr ungenau mit „während der dritten Dekade des I6. Jh.s“ angegeben, ${ }^{\text {II2 }}$ doch da Qui prophetice prompsisti spätestens im Mai I 537 vollendet war, kann eine Bindung des Chorbuches erst nach diesem Zeitpunkt vorgenommen worden sein. Der Brief Wagenrieders stellt also einen terminus post quem für die Bindung des Chorbuches dar.

Zusammen mit der Motette Quid retribuam domino wurden De profundis (ii), 5v. und Deus in adiutorium (4v.) als Teil einer Motettensammlung „en miniatur“ für sechs, fünf und vier Stimmen im Juli I 535 an Albrecht gesandt. Da bislang keine frühere Quelle für die letztgenannten Motetten vorliegt, könnten diese

I 2 Bayerische Staatsbibliothek, Katalog der Musikhandschriften, Bd. I: Chorbücher und Handschriften in chorbuchartiger Notierung, beschrieben von Martin Bente, Marie Louise Göllner, Helmut Hell und Bettina Wackernagel, München I989 (KBM 5/I), S. 7I. 
zwei erhaltenen Motetten zwischen Mai und Juli I 535 entstanden sein. Dass Chorbuch Io die sechsstimmige Widmungsmotette Quid retribuam domino im Gegensatz zu den beiden anderen Motetten nicht enthält, deutet vor allem auf den exzeptionellen Charakter dieses Werkes, schließt aber eine Entstehungszeit für die erhaltenen Kompositionen im erwähnten Zeitrahmen nicht aus. ${ }^{113}$ Diese Motetten - allen voran Quid retribuam domino - scheinen nicht aus einem bereits bestehenden „Pool“ von Kompositionen entnommen worden zu sein. ${ }^{\mathrm{II}}$ Stellt letztere ein Dedikationswerk für den Brandenburg-Preußischen Hof dar, dürfte es sich bei den beiden anderen Psalmvertonungen um jüngst komponierte Motetten handeln, die Senfl aus Wissen um Albrechts besonderes Interesse an neuer Musik ebenfalls übersandte. Die persönliche Verbindung mit dem Widmungsträger wird besonders im Text der sechsstimmigen Motette greifbar, der von Senfl außerordentlich umsichtig im Hinblick auf das vom Herzog erhaltene Geschenk ausgewählt worden war. Die beiden anderen Motetten lassen sich in ihrer musikalischen Struktur ebenfalls auf das in Quid retribuam domino vorgestellte Gottvertrauen deuten. Alle drei Motetten gehören zur Gattung der Psalmmotette, einem Genre, das sich seit den ersten Kompositionen von Josquin Desprez zunehmender Beliebtheit erfreute und im Zuge der Reformation zu einer der wichtigsten Vokalgattungen avancierte. ${ }^{115}$ Wenn Senfl, der bekanntlich selbst eine entscheidende Rolle bei der Josquin-Rezeption in Deutschland gespielt hat, Albrecht nun ausschließlich Psalmmotetten übersendet, ist dies ein weiteres Beispiel einer bewussten Positionierung seiner eigenen Werke neben jenen Josquins. Er reagiert damit nicht nur auf die Beliebtheit solcher Motetten, sondern weiß auch um ihre besondere Wertschätzung in protestantischen Kreisen im Allgemeinen und am Hof in Königsberg im Besonderen.

Kaum weniger spannend und mit aller Vorsicht kann in diesen erhaltenen Dokumenten aus Senfls Umkreis der Mensch hinter der Musik beobachtet werden. Trotz aller Formelhaftigkeit bieten die wenigen Briefe Senfls faszinierende Einblicke in die alltäglichen Denk- und Sichtweisen dieses Mannes, in seine Persönlichkeit und seinen Charakter. Die Souveränität, mit der Senfl I 532 wiederholt seine noch nicht erhaltene Lieferung von 22 preußischen Ellen Damast an-

I 3 Im Gegensatz zu den anderen beiden Motetten ist diese nicht im so genannten Heidelberger Kapellinventar (D-HEu Cod. Pal. germ. 3I8) verzeichnet und auch nicht in einem der Münchner Chorbücher!

I 4 So etwa in Senfl, SW III, S. VI oder Bente, Neue Wege (wie Anm. 4), S. 69.

I 5 Vgl. etwa Walther Dehnhard, Die deutsche Psalmmotette in der Reformationszeit, Wiesbaden I97 I (Neue musikgeschichtliche Forschungen 6) oder Mariko Teramoto, Die Psalmmotettendrucke des Johannes Petrejus in Nürnberg (gedruckt 1538-1542), Tutzing I982 (Frankfurter Beiträge zur Musikwissenschaft IO). 
mahnt, ${ }^{116}$ überrascht angesichts der unterschiedlichen Stellungen der beiden Männer. Obwohl er es nicht an nötigem Respekt mangeln lässt, offenbart Senfl hier eine gewisse Chuzpe und einen in gesundem Selbstbewusstsein wurzelnden Egoismus. Er setzt damit zwar das fragile Gleichgewicht zwischen den beiden Geschenkpartnern aufs Spiel, doch war Albrecht ein derartiger Brief offensichtlich eher peinlich, als dass er darüber verärgert gewesen wäre. ${ }^{117}$

Ähnlich tritt Senfl im Vorfeld des dann schließlich übersandten Geschenkpokals aus dem Jahr I 535 auf. Hier stellt der Brief vom 8. Mai I 535 von Kanzler Johann Apel an Herzog Albrecht eine Wendung in der bislang - vermeintlich bekannten Geschenksituation dar. Sie verändert die Umstände des Geschenkes grundsätzlich, denn es ist $\mathrm{n}$ i c h t der Herzog, der aus besonderer Großzügigkeit einen goldenen Pokal schenkt, es ist Senfl selbst, der um die Anfertigung eines solchen Trinkgeschirrs bittet. Da er Angaben zur Bezahlung macht, scheint er sich des Geschenkwertes durchaus bewusst gewesen zu sein; dennoch hat Senfl auch hier keinerlei Hemmungen, den Wunsch nach einem derart kostbaren Wertgegenstand $\mathrm{zu}$ äußern. Gleichzeitig wird eine weitere Facette von Senfls Persönlichkeit sichtbar: Er scheint Realist gewesen zu sein, der seinen Haushalt nüchtern einschätzen konnte und der offen und frei bekennt, dass er, wenn er nur das Geld bekäme, dieses nicht lange behalten würde. Er wählt daher lieber eine krisensichere Geldanlage, die zudem einen deutlich höheren, individuelleren und ideelleren Erinnerungscharakter hat. So wohlüberlegt Senfls Wunsch nach der angemessenen Bezahlung war, so durchdacht waren sowohl sein Dankbrief als auch seine Geschenkkomposition und so deutlich spricht aus ihm der Respekt für einen der wichtigsten Männer am Beginn der Reformation.

I I6 Senfl fügt als Beleg sogar den Brief Spilbergers bei.

I 7 Für grundsätzliche Überlegungen zum Verhältnis von Schenkendem und Beschenktem siehe Rob C. Wegman, „Musical offerings in the Renaissance“, in EM 33 (2005), S. 425-437. 


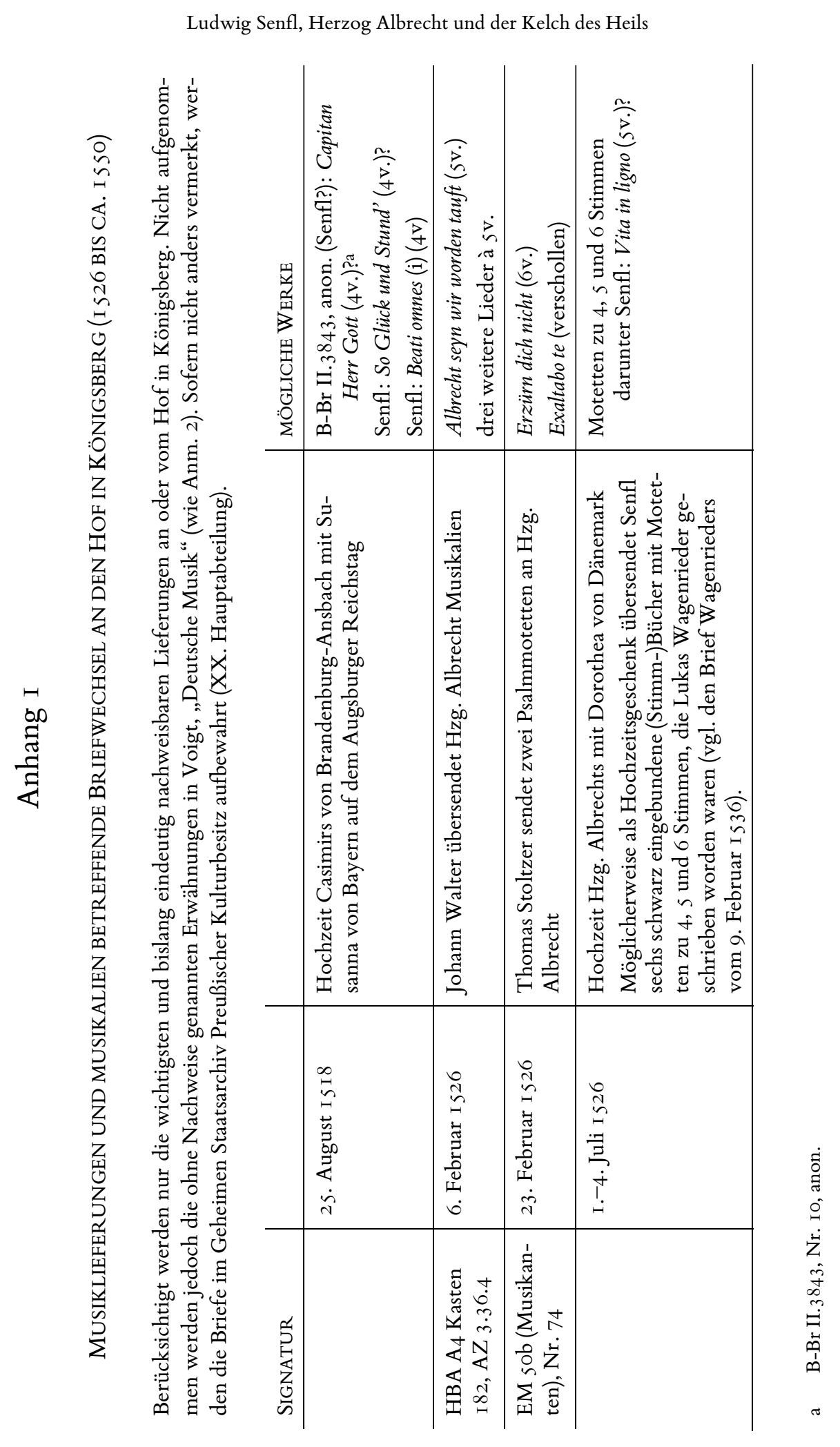


Stefan Gasch

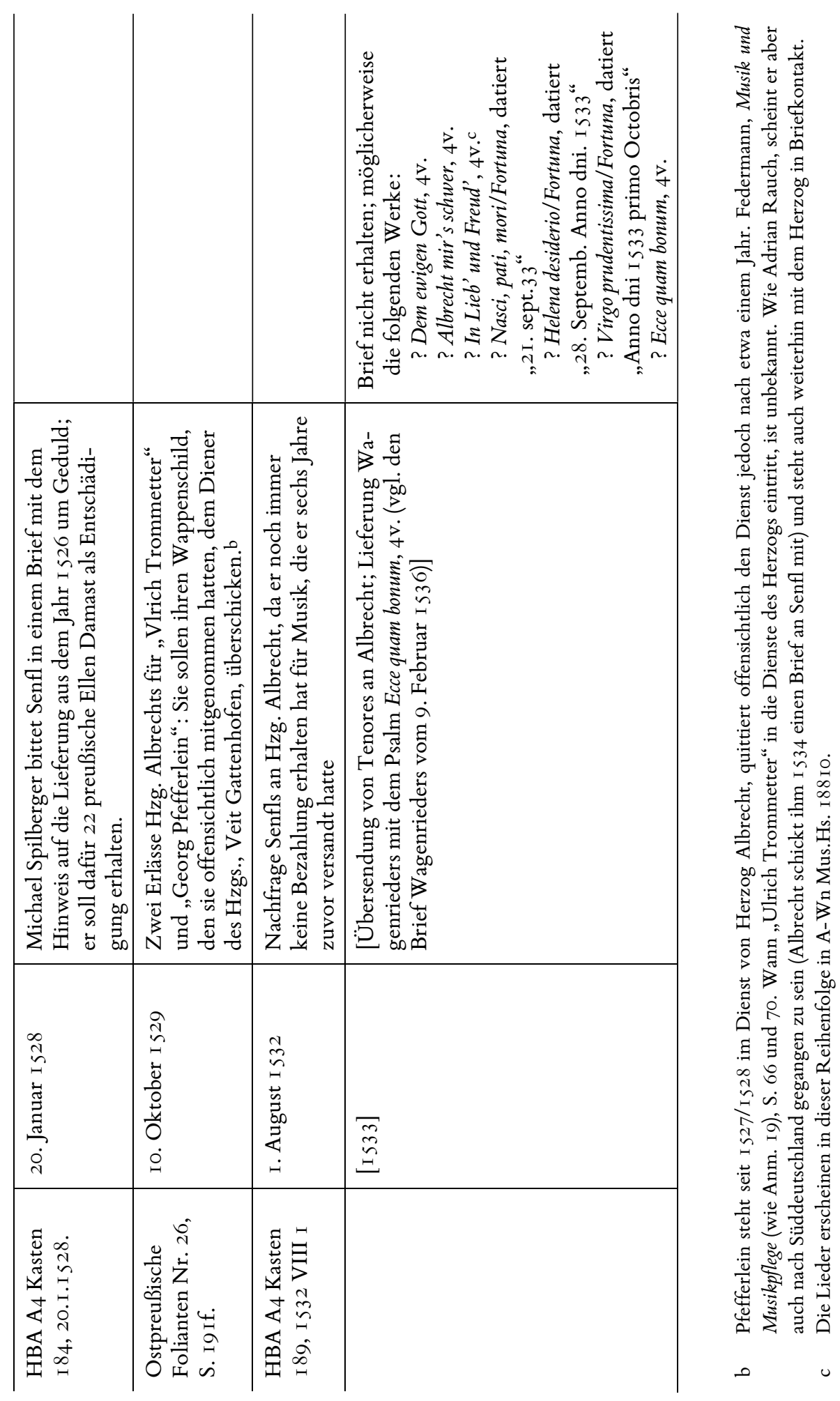

430 
Ludwig Senfl, Herzog Albrecht und der Kelch des Heils

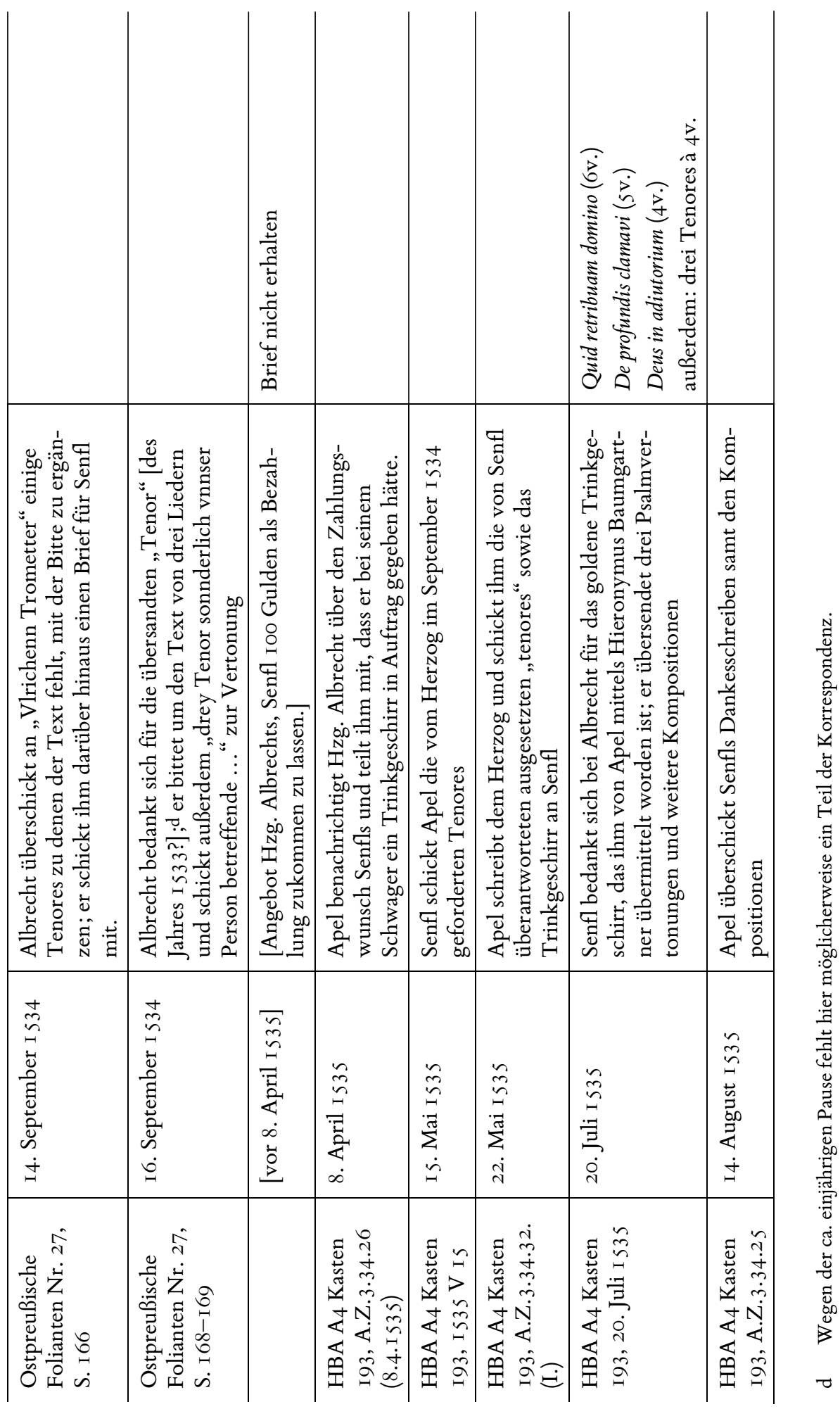


Stefan Gasch

\begin{tabular}{|c|c|c|c|}
\hline & & & 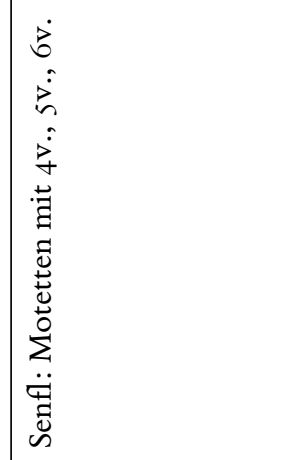 \\
\hline 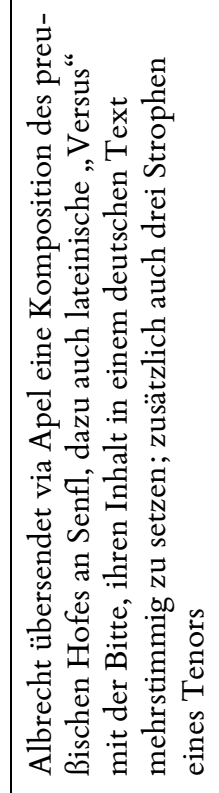 & 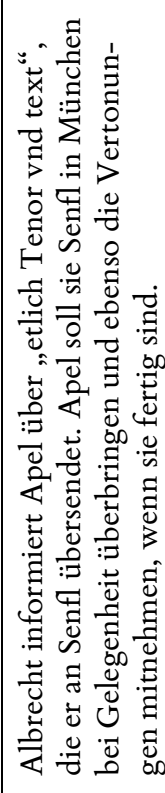 & 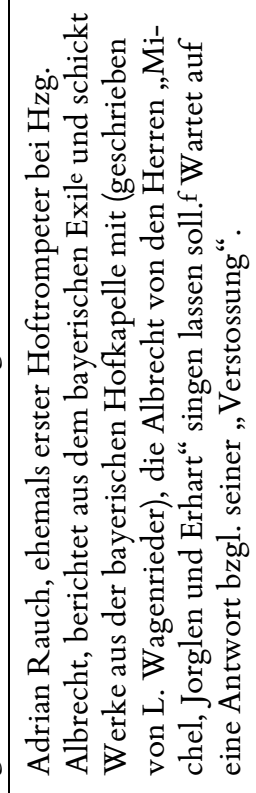 & 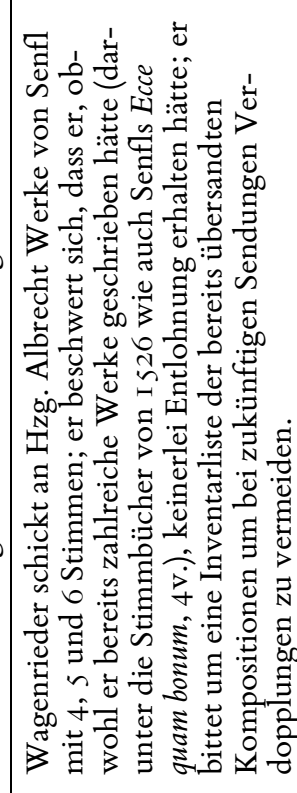 \\
\hline 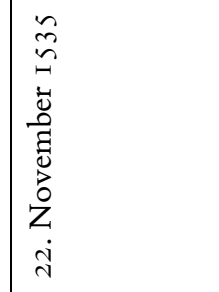 & 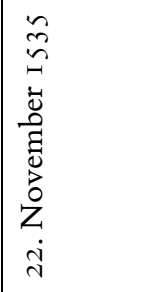 & 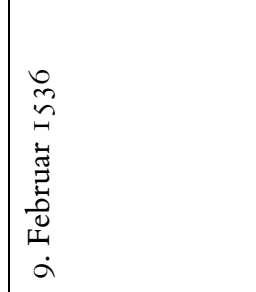 & 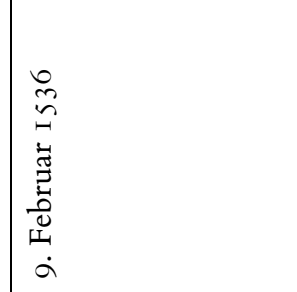 \\
\hline 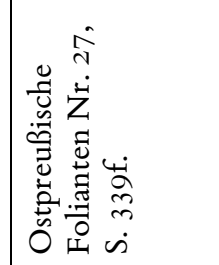 & 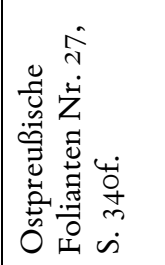 & 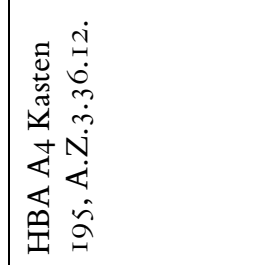 & 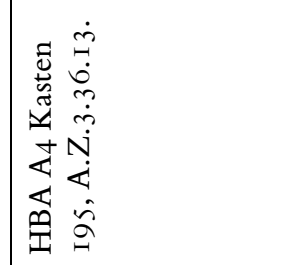 \\
\hline
\end{tabular}


Ludwig Senfl, Herzog Albrecht und der Kelch des Heils

\begin{tabular}{|c|c|c|c|c|c|}
\hline & & 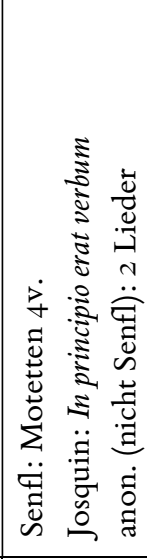 & & 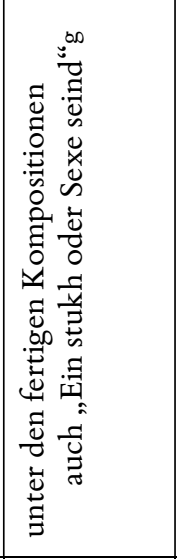 & \\
\hline 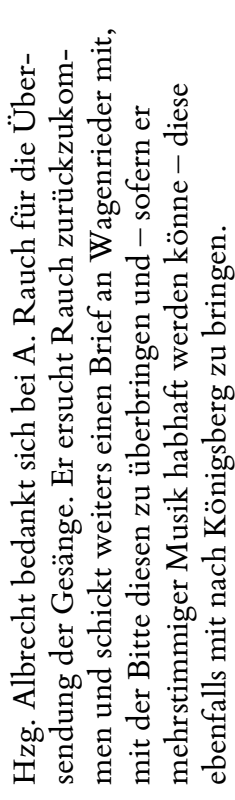 & 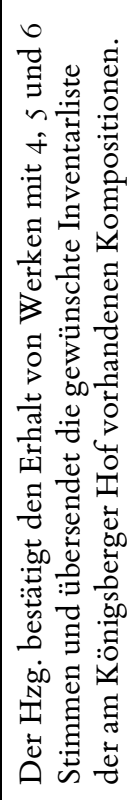 & 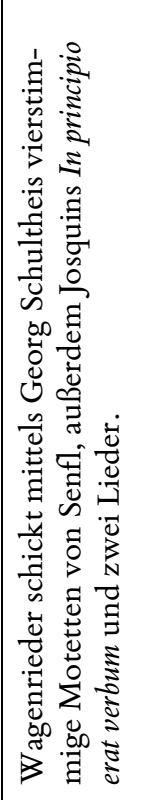 & 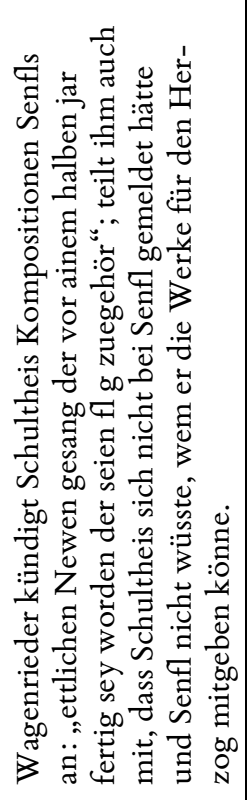 & 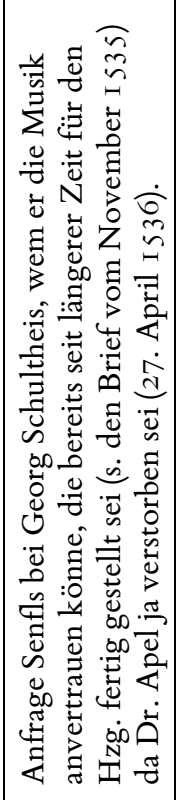 & 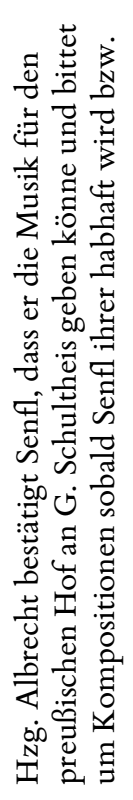 \\
\hline$\underset{\dot{d}}{\stackrel{\vec{n}}{n}}$ & 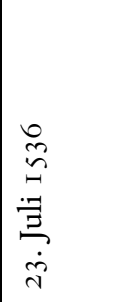 & 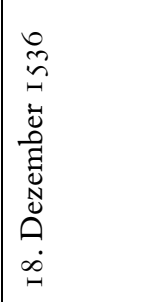 & 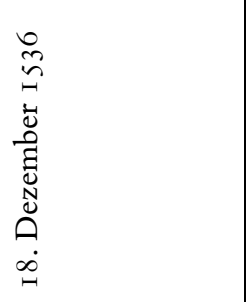 & 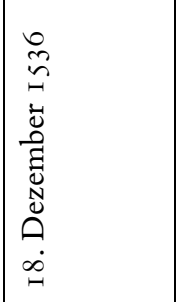 & 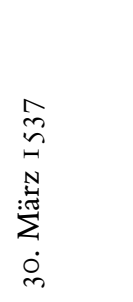 \\
\hline 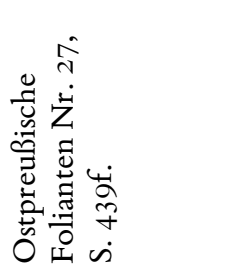 & 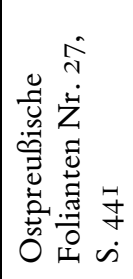 & 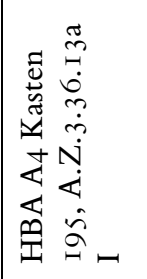 & 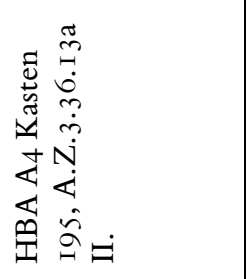 & 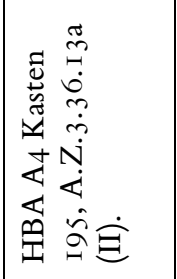 & 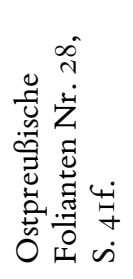 \\
\hline
\end{tabular}


Stefan Gasch

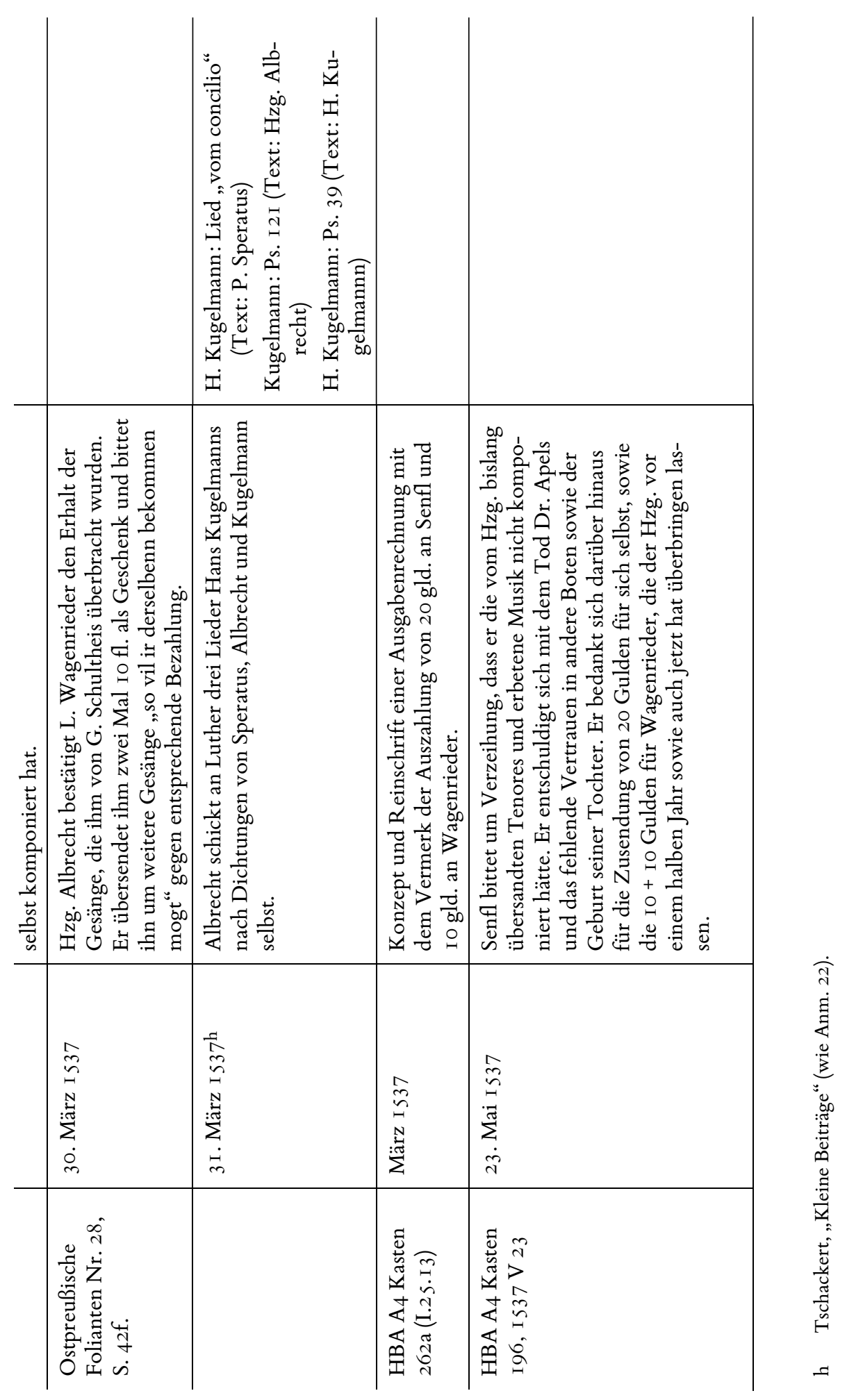


Ludwig Senfl, Herzog Albrecht und der Kelch des Heils

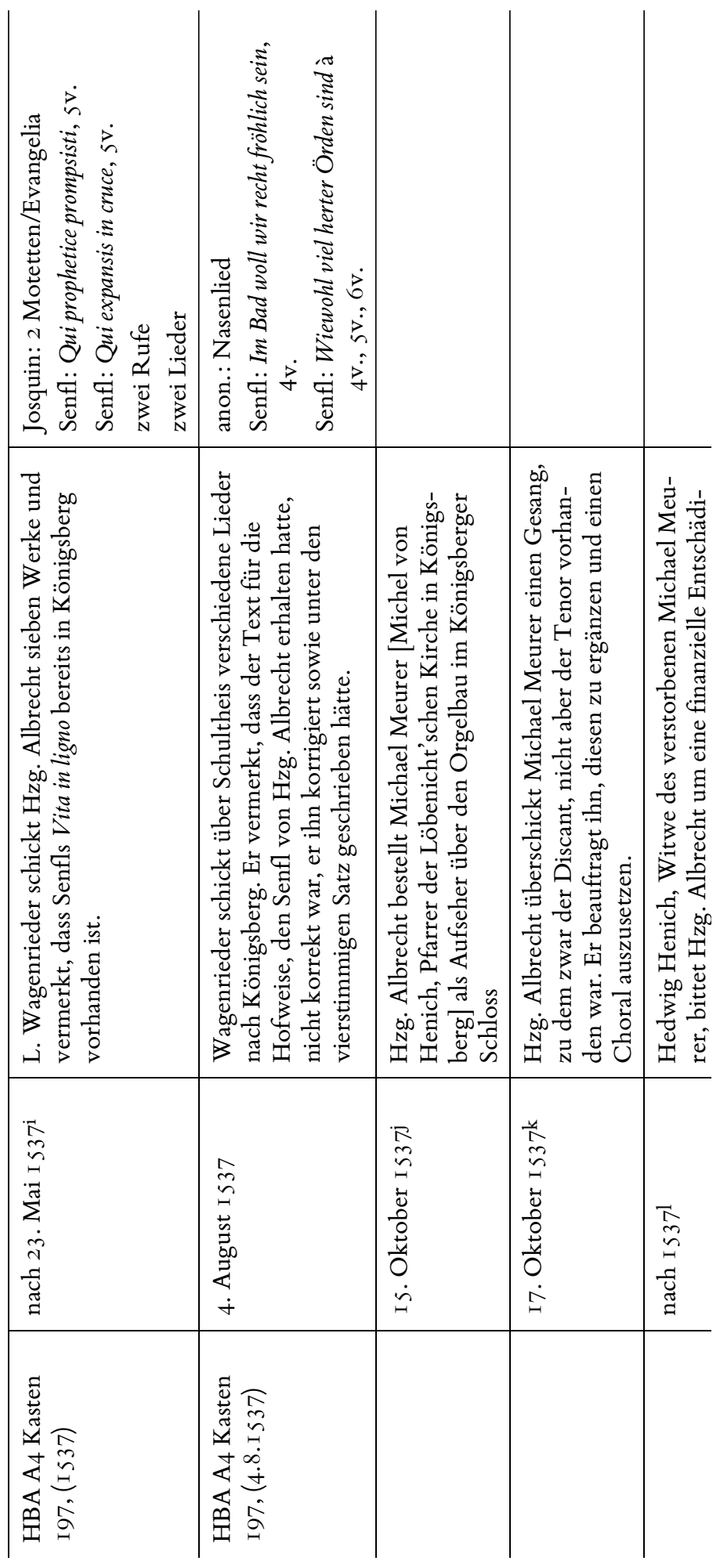

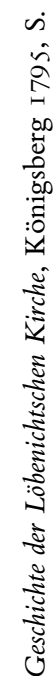

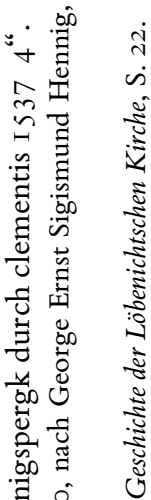

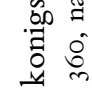

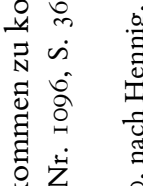

官

i⿱

क्ष

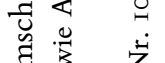

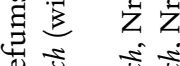

贾 


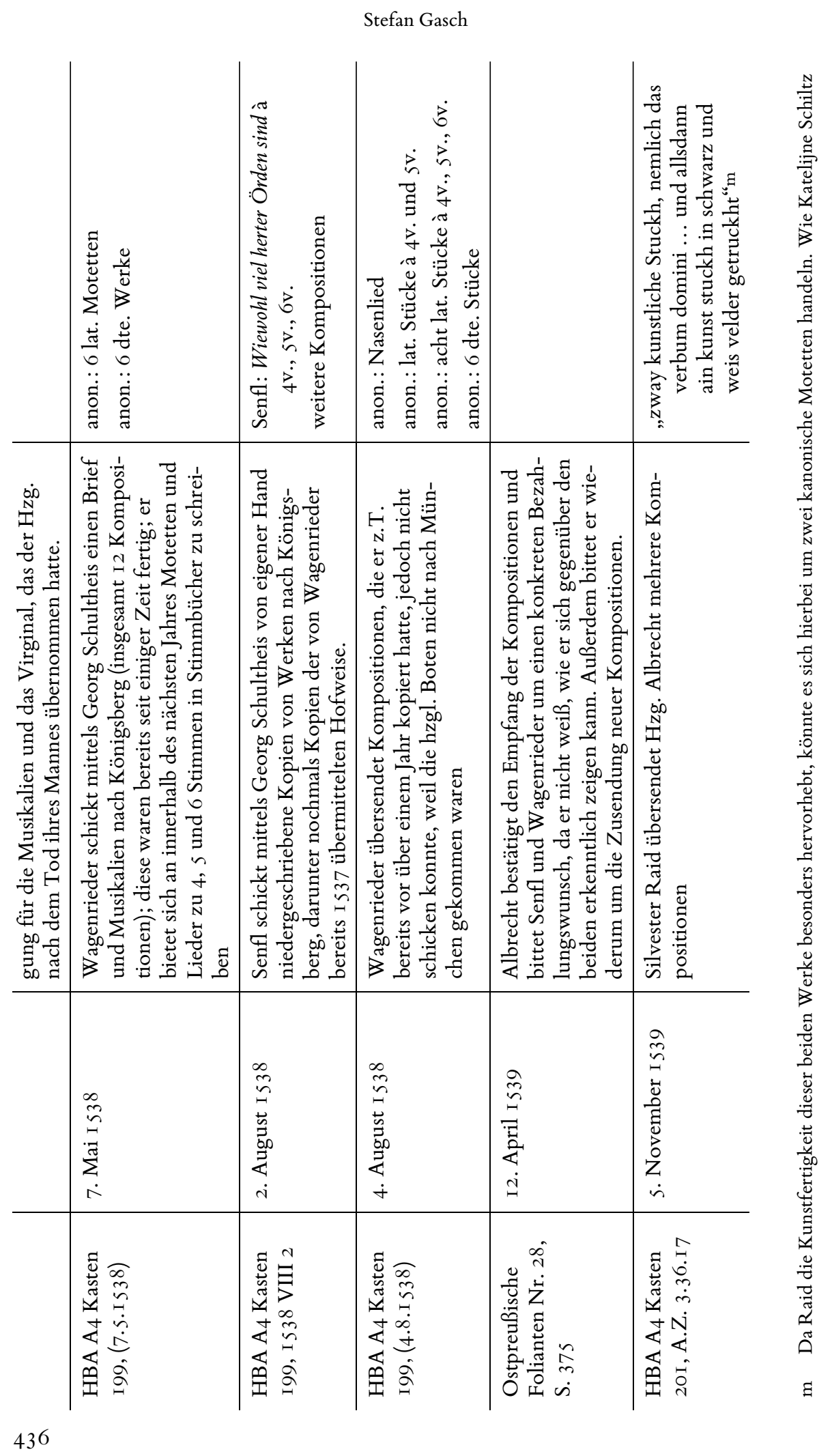


Ludwig Senfl, Herzog Albrecht und der Kelch des Heils
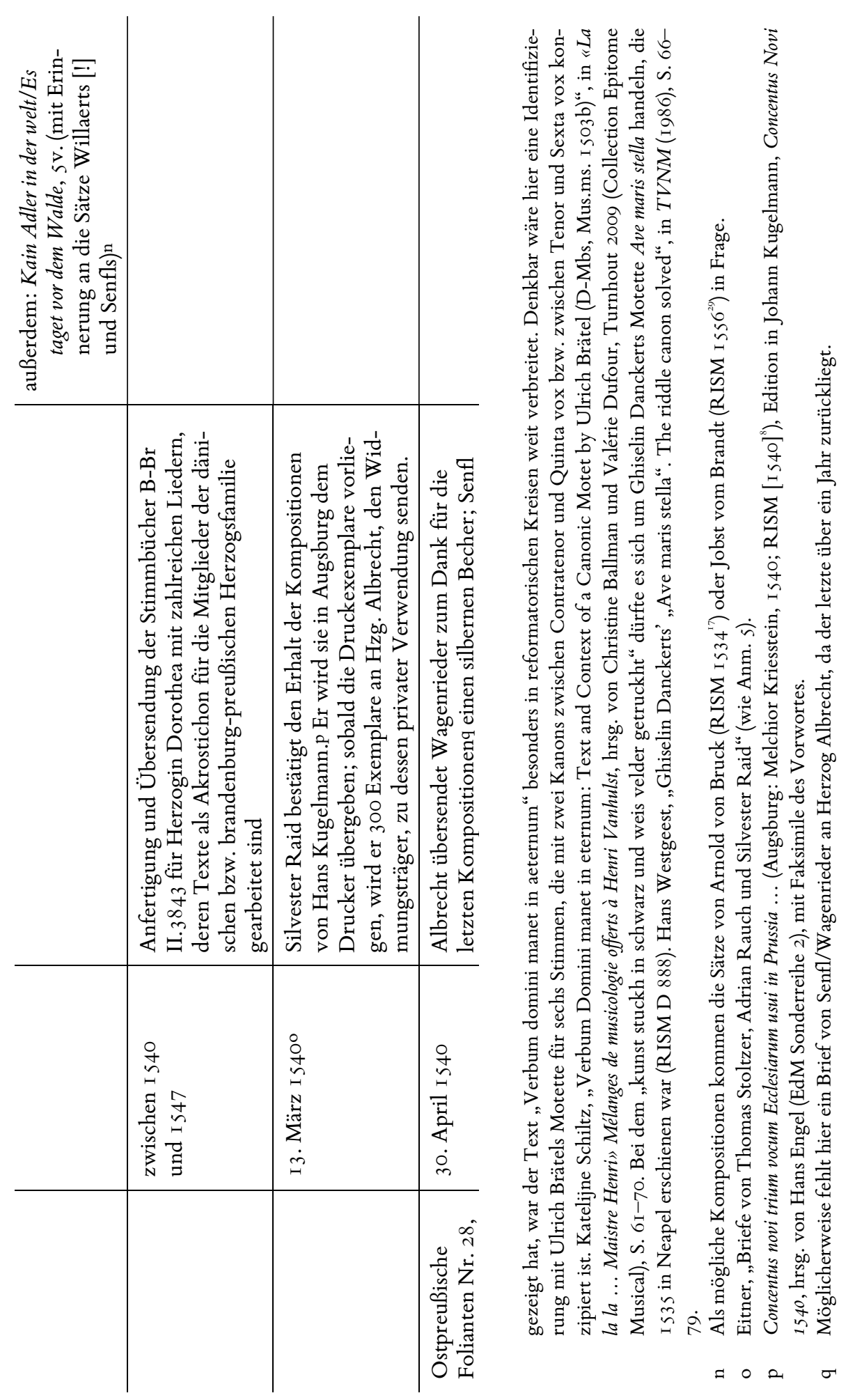
Stefan Gasch

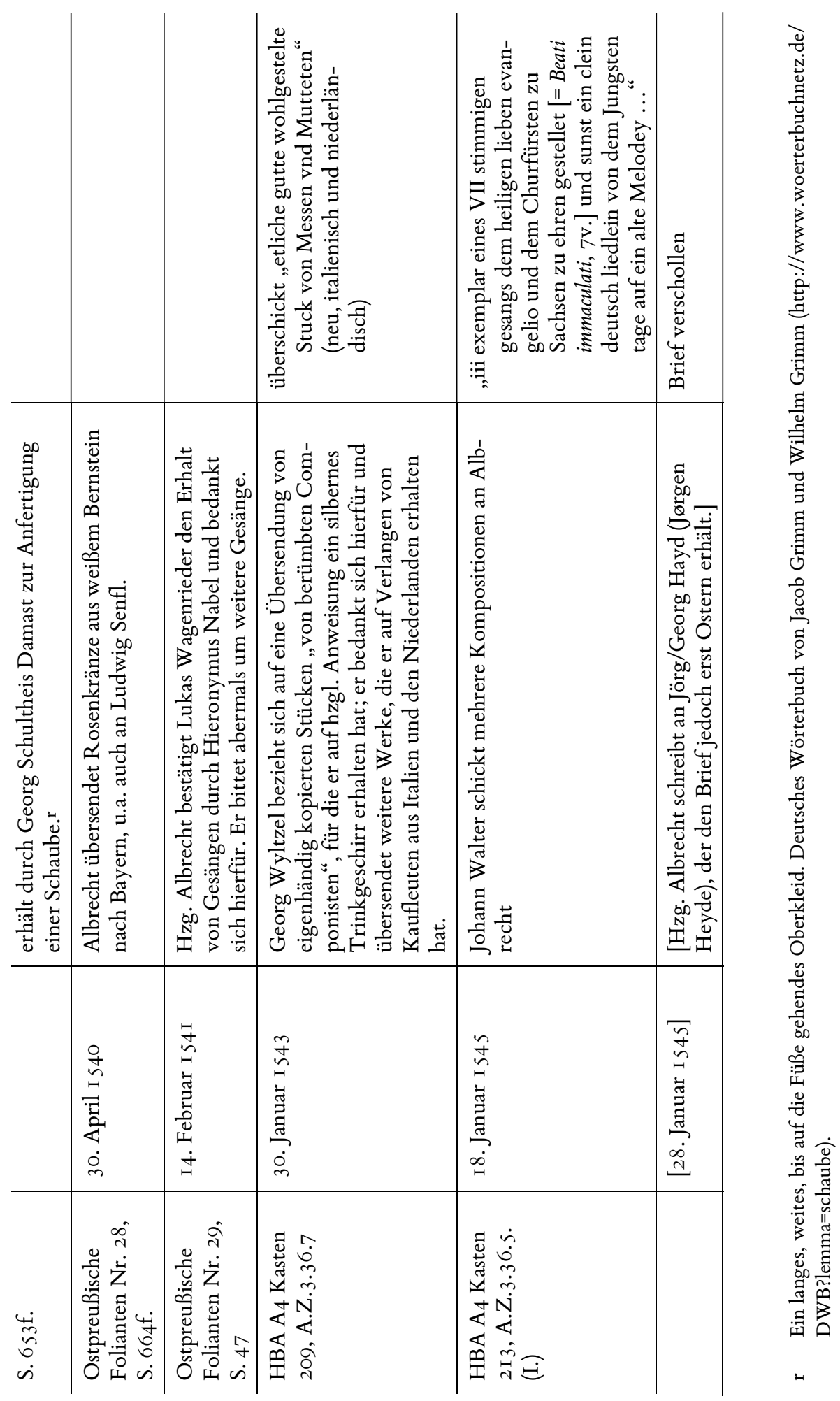

438 
Ludwig Senfl, Herzog Albrecht und der Kelch des Heils

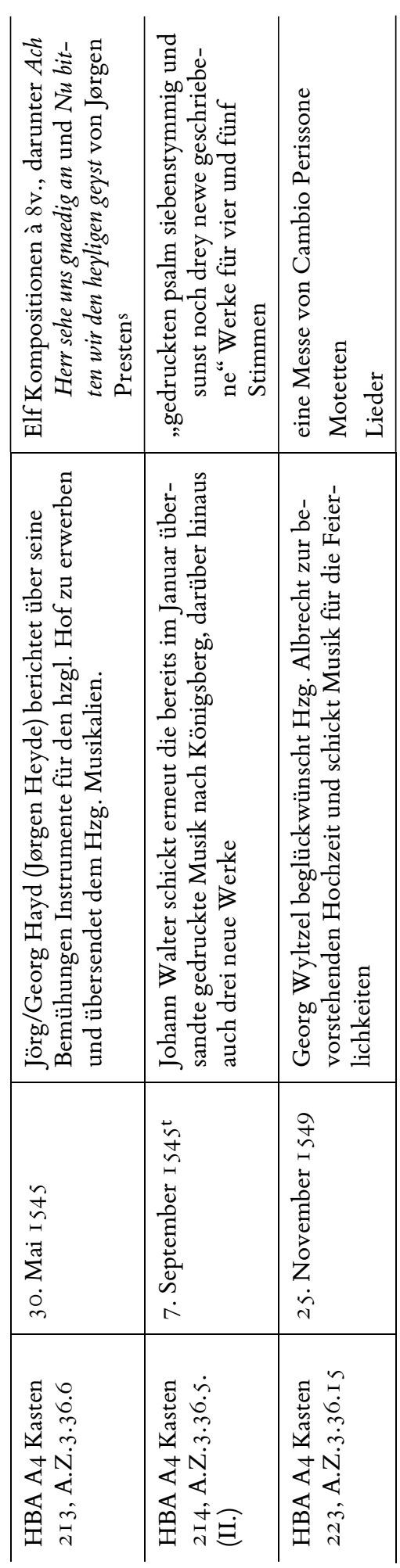




\title{
Anhang 2
}

Brief Johann Walthers an Herzog Albrecht vom 7. September I 545

Berlin, Geheimes Staatsarchiv Preußischer Kulturbesitz, XX. HA HBA A4 Kasten 2 I 4, A.Z.3.36.5. (II.)

Dem durchlauchten / Hochgebornen

Fursten Vnd Herrn / Herrn Albrechten

Marggraffen Zcu Brandenburgk / In

Preussen / Zcu Stetin / Pomern / der

Cassuben vnd wenden / Hertzogen / Burg=

graffen Zcu Nurnbergk Vnd Fursten

Zcu Rugen / meinem gnedigen

herrn

Durchlauchter Hochgeborner Furst. Meine Vntertenige willige dinste sein E. Furstlichen gnaden Willig vnd bereit / Gnediger Her / Ich hab E. F. G. zwey oder dreymal / erstlich durch Hensel lautenschlager gottseligen/ das nechst mal aber / durch des gestrengen Wolffen Von Schonbergs diener einen / Welche briefe ich dem Achtbarn Hochgelarten Doctori Basilio Axt E. F. G leibartzt zcugeschrieben / ettliche geschriebene Vnd gedruckte gesenge zcugeschickt / Weil ich aber darauff nÿe keine antwort empfangen / Weis ich nicht / ob solche gesenge E. F. G. zukome[n] oder nicht. Vbersende derwegen E. F. G. itzt abermals vntertenigklich / einen gedruckten psalm sieben stymmig / vnd sunst auch drey newe geschriebne gestuck funff vnd vierstymmig / welche ich neulich gemacht vntertenigklich bittendt / E. F. G. wollen solche itzt Vnd zcuuor Vberschickten gesenge mit gnedigem gefallen Von mir annehmen / Vnd nach dem ich weis das E. F. G. zcur Musica gnedigen gefallen / auch mein gnediger her sein / Wunsche hiemitt das der Almechtige Gott. E. F. G. mitt gesundem leib Vnd langem leben in erkentnus seines heiligen Worts gnedigklich erhalten Wolle. Amen. Geben Zcu Torga am vij Septembris Im 45 Jar.

E. F. G.

Vntertheniger

Williger

\author{
Joannes Walther des \\ Churfursten Zcu Sachsen \\ geordenter Cantorey \\ Regent
}




\title{
Anhang 3
}

Brief Herzog Albrechts an Lucas Wagenrieder vom I 4. Februar I 54I

Berlin, Geheimes Staatsarchiv Preußischer Kulturbesitz, XX. HA Ostpreußische Folianten 29, S. 47

\begin{abstract}
An Lucassen Wagenreidt den I4 februarÿ [I 54I],

Vnnsernn gruß zuvornn, wirdiger lieber besonnder, wir wollenn euch gnediger meinung nicht verhalten das vnns vnsser underthann hieronimus Nabel etlich gesanng, der vnns sonnderlich angenem gewesen vonn Ewerent wegenn vberantwort, des wir vnns inn gnadenn gegen euch thun bedankenn, wie wir dann gernn offt vil guter newer Composiz vnnd geseng habenn woltenn, so gelangt vnnsers gnedigs fÿrnem vnnd begernn ahn euch, Ir wollet vnns dasselbenn, bißweilenn vil abschreiben lassenn, vnns zuschickenn, vnnd doneben vormelden, wes wir alwegen dem abschreiber darfur widerumb geben, vnnd ob wirs stuckweis oder nach den sexternen belohnen sollenn, So wollenn wir vnns dermassenn mit euch darumb vertragenn, damit dannocht solche müche vnnd arbait vnbelonet nit peibenn sol, vnd daneben solches jnn sonndern gnaden gegenn Ewer person verkennenn, dat[um] königspergk,
\end{abstract}

Commissio Principis 


\begin{abstract}
Ludwig Senfl - although employed at the Catholic Court of Duke Wilhelm IV of Bavaria - maintained a lively correspondence with leading figures of the Reformation such as Martin Luther and Duke Albrecht of Brandenburg-Prussia. The latter, active protectionist of the new religion, especially, in Königsberg and the regions of the Deutschordensstaat (State of the Teutonic Order), several times ordered compositions from Senfl. As hardly any music manuscript remained from Albrecht's time that could give evidence of Senfl's music in Königsberg, we know only little about the particular pieces sent to Duke Albrecht. In order to identify at least some of these compositions and to shed light on the relation between the composer in Munich and the Protestant ruler in Prussia the correspondence, to which two new letters can be added, will be examined afresh. This leads back to the year I 5 I 8 and Senfl's role at the Imperial Diet in Augsburg and his activities during the wedding of Albrecht's brother Kasimir. It will be argued that the anonymously transmitted setting of Capitan Herr Gott Vater mein in B-Br II.3843 for which a transcription is given, might have been composed by Senfl for this wedding. Furthermore, conclusions can be drawn from the close examination of the letters of the mid I 530 os which have impact on some German songs and several motets that reached the Prussian Court between I533 and I 535 and on the manuscript D-Mbs Mus.ms. Io of the Bavarian Court chapel. Furthermore, a letter of Johann Walther to Duke Albrecht dating from 7 September I 545 will be given for the first time in a transcription.
\end{abstract}




\section{WIENER FORUM \\ FÜR ÄLTERE MUSIKGESCHICHTE}

Herausgegeben von Birgit Lodes

Band 4

SENFL-STUDIEN I

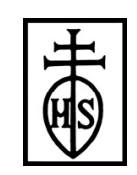

VERLEGT BEI HANS SCHNEIDER · TUTZING 


\title{
SENFL-STUDIEN I
}

\author{
Herausgegeben von \\ Stefan Gasch, Birgit Lodes und Sonja Tröster
}

\begin{abstract}
事
VERLEGT BEI HANS SCHNEIDER · TUTZING

$2 \mathrm{OI} 2$
\end{abstract}


Gedruckt mit Unterstützung

des Dekanats der Philologisch-Kulturwissenschaftlichen Fakultät der Universität Wien

Bibliographische Information Der Deutschen Bibliothek

Die Deutsche Bibliothek verzeichnet diese Publikation in der Deutschen Nationalbibliographie; detaillierte bibliographische Daten Sind im Internet über http://dnb.ddb.de abrufbar.

ISBN 9783862960323

$$
\text { (C) } 2012 \text { by Hans Schneider, D - 82323 Tutzing }
$$

Alle Rechte vorbehalten, insbesondere die des Nachdrucks und der Übersetzung. Ohne schriftliche Genehmigung des Verlages ist es auch nicht gestattet, dieses urheberrechtlich geschützte Werk oder Teile daraus in einem photomechanischen oder sonstigen Reproduktionsverfahren zu vervielfältigen und zu verbreiten.

Die Autorinnen und Autoren sowie Herausgeber haben sich nach Kräften bemüht, alle Publikationsrechte einzuholen. Sollten dennoch Urheberrechte verletzt worden sein, bitten wir die betroffenen Personen oder Institutionen, sich mit uns in Verbindung zu setzen.

\section{Redaktion: Stefan Gasch \& Sonja Tröster$$
\text { Satz: Stefan Gasch }
$$

Notensatz: Stefan Gasch \& Sonja Tröster

Druck: Offsetdruck Andreas Bokor, D-83646 Bad Tölz

Bindung: Buchbinderei Norbert Klotz, D-89343 Jettingen-Scheppach

Gedruckt auf alterungsbeständigem Papier 


\section{Inhalt}

\section{LEBENSWELTEN}

\section{KLAUS PIETSCHMANN}

„genannt Schweitzer“ - Eine nationale Karrierestrategie Ludwig Senfls?

ELISABETH GISELBRECHT / L. ELIZABETH UPPER

Glittering Woodcuts and Moveable Music:

Decoding the Elaborate Printing Techniques, Purpose, and Patronage

of the Liber Selectarum Cantionum

GRANTLEY MCDONALD

The Metrical Harmonice of Wolfgang Gräfinger and Ludwig Senfl in the Conjunction of Humanism, Neoplatonism, and Nicodemism

CLEMENS MÜLLER

Eine Humanistenode Wolfgang Gräfingers, notiert von Joachim Vadian

\section{EINFLÜSSE}

\section{NICOLE SCHWINDT}

Einer unter anderen - Senfls früheste Lieder

ANDREA LINDMAYR-BRANDL

Ludwig Senfl und seine Freunde:

Amulatio und Individuatio im Frühen Deutschen Lied

ANDREAS PFISTERER

Chanson combinative und Volksliedsatz:

$\mathrm{Zu}$ einem Liedtypus bei Isaac und Senfl

DAVID J. BURN

Ludwig Senfl and the Mass Proper: Aspects of Chronology

THOMAS SCHMIDT-BESTE

Ludwig Senfl und die Tradition der Cantus-Firmus-Motette 


\section{GLAUBENSFRAGEN}

\section{WOLFGANG FUHRMANN}

Die Suche nach musikalischer und religiöser Identität

in Ludwig Senfls Psalmmotetten

BIRGIT LODES

Zur katholischen Psalmmotette der I $520 e r$ Jahre:

Othmar Luscinius und die Fugger

STEFAN GASCH

Ludwig Senfl, Herzog Albrecht und der Kelch des Heils

SONJA TRÖSTER

Mag ich Unglück nit widerstan - Liebe, Tod und Glaubensfragen als Komponenten einer Lied-Karriere im I6. Jahrhundert

\section{KLANGWELTEN}

FABRICE FITCH

Senfl in the Studio

PERSONEN- UND WERKREGISTER 